\title{
Wettability alteration and retention of mixed polymer-grafted silica nanoparticles onto oil-wet porous medium
}

\author{
Hamid Daneshmand ${ }^{1} \cdot$ Masoud Rezaeinasab ${ }^{2} \cdot$ Masoud Asgary $^{3} \cdot$ Meysam Karimi $^{4}$
}

Received: 14 September 2020 / Accepted: 8 December 2020 / Published online: 13 February 2021

(c) The Author(s) 2021

\begin{abstract}
Enhanced oil recovery (EOR) processes are applied to recover trapped or residual oil in the reservoir rocks after primary and secondary recovery methods. Changing the wettability of the rock from oil-wet to water-wet is named wettability alteration. It is an important factor for EOR. Due to their unique properties, nanoparticles have gained great attention for improving oil recovery. Despite the promising results, the main challenges of applying nanoparticles are related to the colloidal stability of the nanofluids in the harsh conditions of the reservoirs. In recent years, polymer-grafted nanoparticles have been considered as novel promising materials for EOR. The obtained results showed that adding a hydrophobic agent trimethoxy (propyl) silane on the surface of modified silica nanoparticles with polyethylene glycol methyl ether has an effective role in improving retention and wettability alteration, especially in the oil-wet substrate due to hydrophobic interaction. The modified silica nanoparticle by mixed polyethylene glycol methyl ether ( $\mathrm{Mn} \sim 5000)$ and trimethoxy (propyl) silane showed a proper performance at a concentration of $1000 \mathrm{ppm}$ and a salinity range of $2000-40,000 \mathrm{ppm}$. The obtained findings can help for a better understanding of the silica nanofluid modification with both hydrophilic and hydrophobic agents for the EOR application of near-wellbore.
\end{abstract}

Keywords Wettability alteration $\cdot$ Retention $\cdot$ Silica nanoparticle $\cdot$ Surface modification $\cdot$ Enhanced oil recovery

\section{Introduction}

Hydrocarbon resources are the main source of primary energy, contributing to the most used energy in the world (Aftab et al. 2017; Agista et al. 2018; Patel et al. 2015). Injection of conventional water into oil reservoirs has been considered as the most commonly used secondary recovery method which can extract one-third of oil from the reservoir rocks (Kazemzadeh et al. 2018). Hydrocarbon resources are the most demanded non-renewable and limited energy

Edited by Xiu-Qiu Peng

Hamid Daneshmand

hamiddaneshmand1370@gmail.com

Department of Physics, University of Tehran, Tehran, Iran

2 Department of Chemistry, Faculty of Science, Yazd University, Yazd, Iran

3 Department of Materials Engineering, Tarbiat Modares University, Tehran, Iran

4 Department of Material Science, Shahreza Branch, Islamic Azad University, Isfahan, Iran sources around the world. Hence, it is essential to develop novel methods for the recovery of the residual oil from the rock pore space (Guo et al. 2016). There are several methodologies used for increasing the amount of crude oil named enhanced oil recovery (EOR). EOR studies have been focused on the reduction of interfacial tension between water and oil (Buijse et al. 2012), viscosity control (Jamaloei and Kharrat 2010), and wettability alteration of the reservoir rocks which are effective parameters to enhance hydrocarbon production (Zhao et al. 2010).

Nanoparticles are one of the main nanomaterials that received the most attention for EOR purposes (Zhang et al. 2018). Due to their unique properties, they can penetrate the small pores of the reservoir rocks and alter the wettability of rock from oil-wet to water-wet state (Zargartalebi et al. 2015). As a result, trapped oil is extracted from the pore rock along with a decrease in the capillary forces (Wang et al. 2005). Most researches have been studied the capability of metal oxide nanoparticles $\left(\mathrm{SiO}_{2}, \mathrm{Al}_{2} \mathrm{O}_{3}, \mathrm{ZnO}, \mathrm{TiO}_{2}, \mathrm{NiO}\right.$, $\mathrm{ZrO}_{2}$, and $\mathrm{Fe}_{3} \mathrm{O}_{4}$ ) for EOR purposes (Giraldo et al. 2013; Iglauer et al. 2015; Nwidee et al. 2017). 
The main challenge for using the nanofluid in real conditions of the reservoir is related to the colloidal suspension stability and the agglomeration of nanoparticles (Ehtesabi et al. 2014; Hendraningrat and Torsæter 2015; Ju et al. 2002; Miranda et al. 2012). The stability of nanoparticles is based on the electrostatic double-layer forces which can be affected at high-salinity. In this condition, the ionic strength of high salt concentration reduces electrostatic repulsive force between nanoparticles (Al-Anssari et al. 2016; Ju et al. 2006) (Fig. 1a). Furthermore, nanoparticles have a high tendency to aggregate. This is because of the high surfaceto-volume ratio and the existence of mutual van der Waals forces between nanoparticles (Hendraningrat and Torsæter 2014; Ranka et al. 2015). Therefore, aggregation phenomena in nanoparticles can close pore throat and diminish permeability that is essential for retention and subsequently wettability alteration of rocks (Songolzadeh and Moghadasi 2017). The aggregation effect of nanoparticles can be reduced by special methods. Recent studies have proposed different approaches to modify the nanoparticle surface by mixing it with a polymer or surfactant that renders a better performance than unmodified nanoparticles (Al-Anssari et al. 2017a, b, c; Al-Anssari et al. 2018; Hendraningrat et al. 2012). The grafting surface of the nanoparticle with a long-chain polymer is studied as a novel approach that not only improves the stability of nanofluid but also increases flowability through the porous media at reservoir conditions.
For example, Binks et al. (Binks and Rodrigues 2007; Binks et al. 2007) showed that silica nanoparticles stabilize oil-in-water macro-emulsions when blended with an anionic or cationic surfactant. Johnston et al. (Bagaria et al. 2013; Xue et al. 2014) studied various iron-oxide nanoparticles grafted with amphiphilic and charged polymers. They reported a decrease in the interfacial tension between oil and water. Also, they studied the effect of iron-oxide clusters and silica nanoparticles coated with poly [oligo (ethylene oxide) monomethyl ether methacrylate] and showed a significant reduction in interfacial tension at very low nanoparticle concentrations (1-10 ppm) (Foster et al. 2014; Kim and Krishnamoorti 2015). Lead et al. (Mirshahghassemi and Lead 2015; Palchoudhury and Lead 2014) reported polymer-coated nanoparticles that have the potential to separate oil-water mixtures. Behzadi and coworkers (Behzadi and Mohammadi 2016) studied the modified $\mathrm{SiO}_{2}$ with mixed polyethylene glycol and propyl chains. They reported enhancing oil recovery and wettability alteration of the glass substrate. Choi et al. (Choi et al. 2017) studied that modified $\mathrm{SiO}_{2}$ nanoparticles with a zwitterionic polymer. The results showed that these modified nanoparticles could improve the oil recovery by $5 \%$ volume with 0.3 psi reduction in pressure. Moreover, the retention of polymer-grafted nanoparticles onto the carbonate surface altered the wettability. They found that the oil recovery was improved by $10.8 \%$ (a)

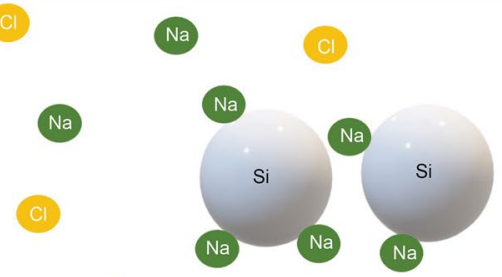

Aggregation

(c)

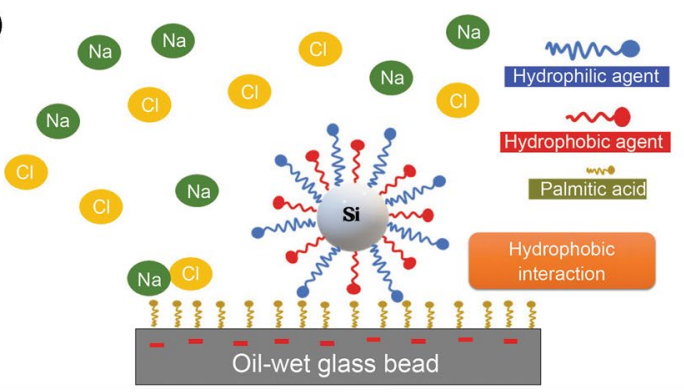

(b)

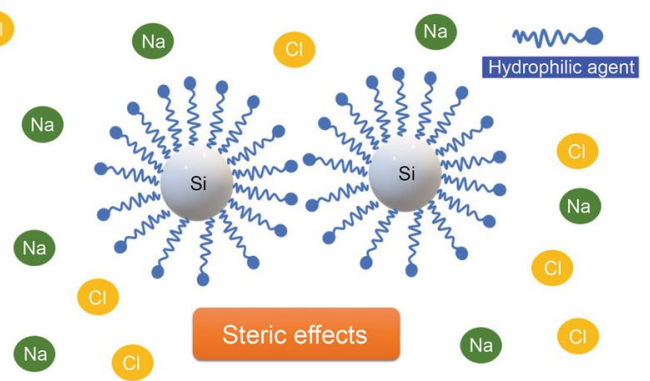

(d)

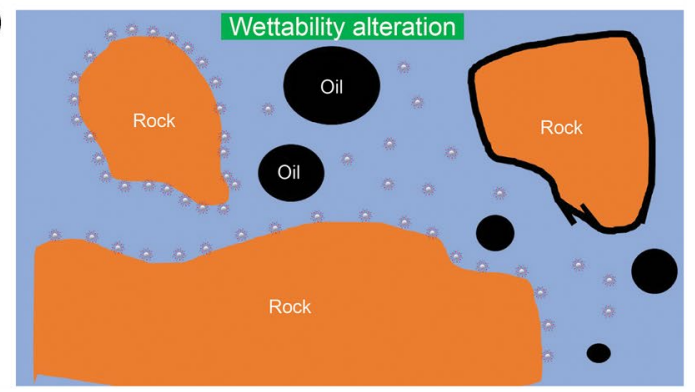

Fig. 1 Schematic of the EOR process for wettability alteration of reservoir rock with mixed polymer-grafted silica nanoparticles. a The aggregation of nanoparticles in the condition of the reservoir. $\mathbf{b}$ The addition of hydrophilic polymer on the surface of silica nanoparticle to prevent aggregation with steric stabilizer effect. $\mathbf{c}$ The addition of hydrophobic polymer on the surface of silica nanoparticle for increasing retention on the oil-wet substrate due to hydrophobic interaction. d Extracted oil from reservoir rock with retention of mixed polymer-grafted silica nanoparticles due to wettability alteration 
with $0.03 \mathrm{wt} \%$ of nanocomposite additives in comparison with the seawater. El-Hoshoudy et al. (2016) studied the performance of polyacrylamide polymer-grafted $\mathrm{SiO}_{2}$ nanoparticles. Results showed that grafted nanoparticles indicated high anti-salinity, resistance against temperature, and shear resistance properties with thickening behavior. Besides, the wettability of the oil-wet rock surface can be altered to water-wet at high salinity of $40,000 \mathrm{ppm}$ and a high temperature of $90{ }^{\circ} \mathrm{C}$. The oil recovery of $2000 \mathrm{mg} / \mathrm{L}$ of polymer-grafted $\mathrm{SiO}_{2}$ was reported $60 \%$ of residual oil saturation. However, despite valuable researches, further studies are needed for polymer-modified nanoparticles for designing more efficient polymer-coated nanoparticles. Researchers mostly focused on the increase in the retention of nanofluid based on the colloidal stability using polymer modification (Fig. 1b). In other words, adding the steric effects to nanofluid for colloidal stability is the main reason for using grafted polymers. It is important to note that reservoir rocks are often hydrophobic. As a result, the addition of the hydrophobic agent to the nanoparticle surface leading the hydrophobic interaction between nanoparticles and reservoir rock. This observation can increase the retention of nanoparticles. In this work, polymer and also hydrophobic agents were used to modify the surface of silica nanoparticles to increase the retention of nanoparticles and improve the wettability alteration. This procedure leads to the addition of both steric effects and hydrophobic interaction between silica nanoparticles and oil-wet substrate, respectively (Fig. 1c).

Here, we propose that properly designed, polymer-coated nanoparticles can alter the wettability of substrate from an oil-wet state to a water-wet one (Fig. 1d). We prepared a series of silica nanoparticles with a mixture of hydrophilic and hydrophobic chains covalently grafted to the surface. We found that nanoparticles coated with a mixture of hydrophilic polymer chains and hydrophobic chains are more efficient in comparison with nanoparticles coated with only hydrophilic polymer chains in the oil-wet system due to hydrophobic interaction. In this study, the experimental results and the characterization of silica nanoparticles modified with polymer or substrates are presented in detail. Thus, wettability alteration and retention of polymer-coated nanoparticles are discussed based on the effective parameters such as the concentration of modified nanoparticles, time of surface modification, and salinity. All parameters were studied at ambient conditions. It is notable to the fact that high pressures and temperature can dominate at reservoir conditions which consequently affect nanofluid retention. Therefore, the efficiency of polymer-coated nanoparticles can be different from the ambient condition in comparison with the reservoir conditions. Also, the heterogeneity of rocks and the rate of nanoflow have a significant effect on the retention and distribution of particles.

\section{Experimental details}

\subsection{Materials}

Non-porous silica nanoparticles (AEROSIL ${ }^{\circledR} 200$ ) were used with a specific area of $200 \pm 25 \mathrm{~m}^{2} / \mathrm{g}$. The average primary particle size was $12 \mathrm{~nm}$. Solid-glass bead (borosilicate, diam. $3 \mathrm{~mm}$ ), polyethylene glycol methyl ether averages $\mathrm{Mn} \sim 2000$ (PEG1), polyethylene glycol methyl ether averages $\mathrm{Mn} \sim 5000$ (PEG2), 3-glycidoxypropyltrimethoxysilane (GPTMS, 98\%), and trimethoxy (propyl) silane (C3S, 97\%) were purchased from Sigma-Aldrich. Acetic acid (glacial, $100.0 \%$ ), $n$-hexane $(99.9 \%)$, sulfuric acid (98\%), hydrogen peroxide (30\%), and ethanol (99.9\%) were provided from Merck. Acetonitrile (99.9\%) and palmitic acid (99\%) were, respectively, acquired from Ameretat Shimi (Iran) and CARLO EBRA (Italy). All reagents used in this work were of analytical grade and applied without further purification.

\subsection{Modification of silica nanoparticles}

The silanol groups, $\mathrm{Si}-\mathrm{OH}$, on the surface of silica nanoparticles can interact with used polymers. To make a specific interaction between silica nanoparticles and polymers, silanization strategies are also used for the modification of polyethylene glycol methyl ether (PEG1 or PEG2) in which their surface is silanized and functionalized with silane group. The details of this procedure are summarized as follows. A mixture of dried polyethylene glycol methyl ether $(30 \mathrm{~g})$, GPTMS $(4 \mathrm{~g})$, and acetic acid $(0.2 \mathrm{~mL})$ as a catalyzer was placed in the flask containing $150 \mathrm{~mL}$ of acetonitrile solution. The obtained solution was refluxed at $90{ }^{\circ} \mathrm{C}$ with continuous stirring for $6 \mathrm{~h}$ (Fig. 2a). C3S was added (5 mL) directly to silica distilled water solution (5 wt\%) as the silane group source and the obtained solution then stirring for $5 \mathrm{~h}$ (Fig. 2b). To modify silica with polyethylene glycol methyl ether, the functionalized polyethylene glycol methyl ether was added to silica distilled water solution ( $5 \mathrm{wt} \%)$ and stirred for $10 \mathrm{~h}$. This strategy is also used for the modification of silica with the mixed polymer of polyethylene glycol methyl ether and propyl chains (Fig. 2c). The pH of the solution was adjusted at 9.5 using $\mathrm{NaOH}$ and the temperature of reflux was set at $80^{\circ} \mathrm{C}$. Finally, the obtained solution was centrifuged and washed three times with ethanol (Behzadi and Mohammadi 2016).

Three types of modified silica including the modified silica nanoparticle by PEG1, the modified silica nanoparticle by mixed PEG1 and C3S, and the modified silica nanoparticle by mixed PEG2 and $\mathrm{C} 3 \mathrm{~S}$ were prepared for the treatment of substrates. 
(a)

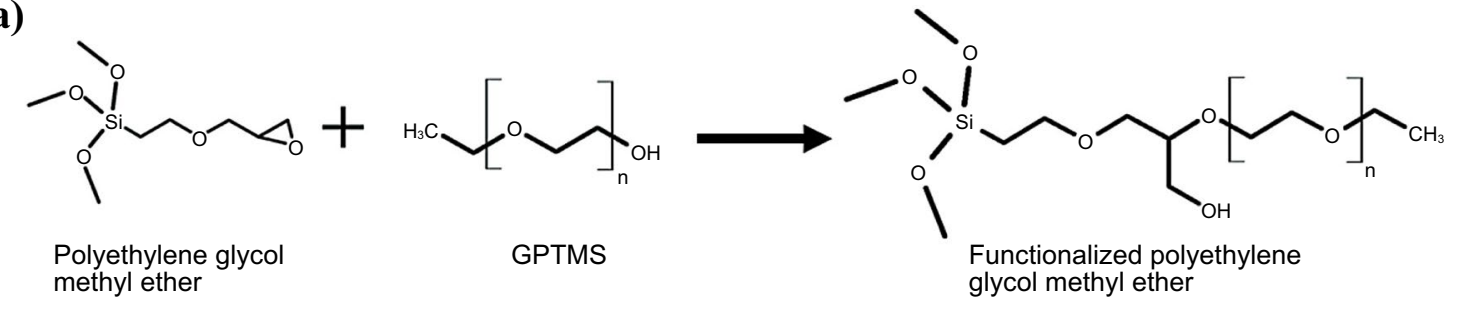

(b)

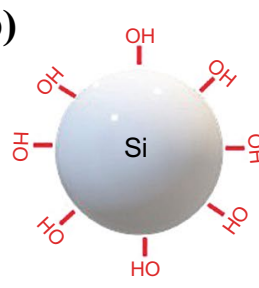<smiles>CCCS(OC)(OC)OC</smiles>

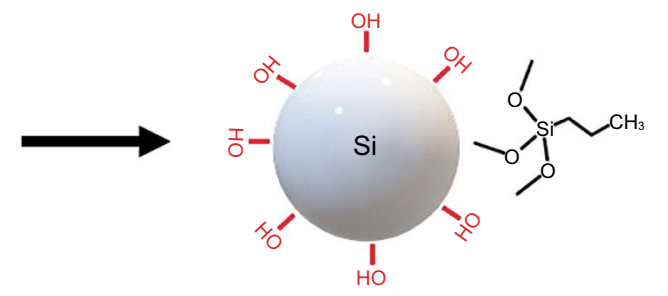

(c)

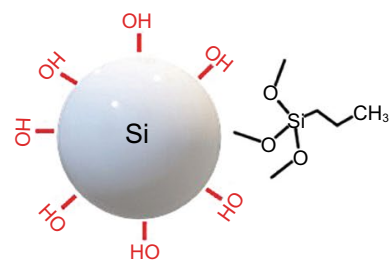

C3S grafted silica<smiles>CCOCCCC(CO)CCOCCS(CCOCC)(OC)OC</smiles>

Functionalized polyethylene glycol methyl ether

Mixed functionalized polyethylene glycol methyl ether/C3S grafted silica
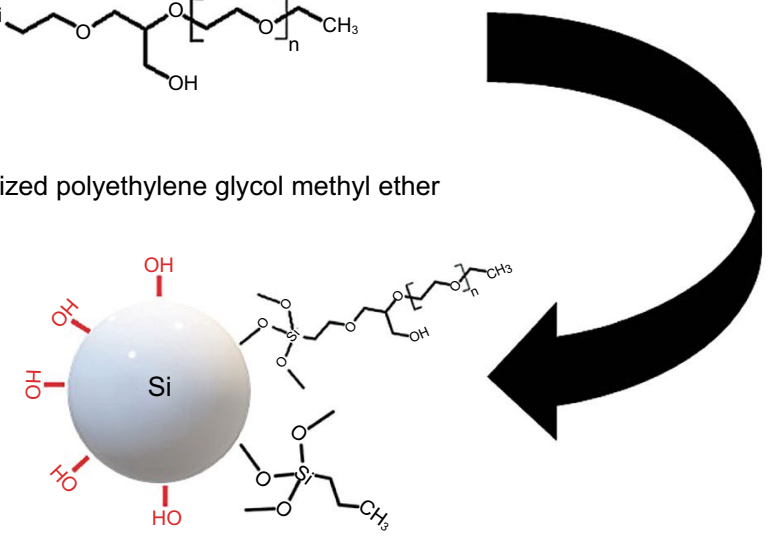

Fig. 2 Chemical reaction steps: a The functionalized polyethylene glycol methyl ether by 3-glycidoxypropyltrimethoxysilane (GPTMS), b The modified silica by trimethoxy (propyl) silane (C3S), and $\mathbf{c}$ The addition of functionalized polyethylene glycol methyl ether on the surface of the modified silica with $\mathrm{C} 3 \mathrm{~S}$

\subsection{Modification of glass bead to oil-wet glass bead}

Due to the instability of reservoir rocks in the measurement of the contact angle, borosilicate glass beads were used to replace sandstone (Jamaloei and Kharrat 2010). The reason for the application of this glass bead is that the reservoir rock has a porous medium. Thus, these materials can be used for the simulation of the porosity condition. Sandstone is mainly composed of silica, which is also a borosilicate glass bead. The oleophilicity of reservoir rock is due to the fact that fatty acids are adsorbed over time (Iglauer et al. 2015). Thus, palmitic acid was used to modify the glass beads. Before the treatment by nanofluids, the glass beads were washed with the aid of ultrasonic agitation in acetone, ethanol, and distilled water for $30 \mathrm{~min}$. Then, it was dried under the ambient condition in an oven. To obtain a strongly water-wet surface, the glass beads were refluxed in the piranha solution, a 3:1 mixture of sulfuric acid (98\%) and hydrogen peroxide (30\%), at $250{ }^{\circ} \mathrm{C}$ for $24 \mathrm{~h}$ (Shi et al. 2010). Because the piranha solution is a mixture of a strong oxidizing agent, it will remove most residues of organic substrates, as well as it will hydroxylate the used surfaces making them highly hydrophilic. After that, the glass beads were washed with distilled water and ethanol and dried in an oven. The treated glass beads by the piranha solution were immersed in the palmitic acid solution $(0.1 \mathrm{M})$ dissolved in n-hexane and refluxed at $90{ }^{\circ} \mathrm{C}$ for $24 \mathrm{~h}$ (Arslan et al. 2006). Finally, the oil-wet glass beads were washed by ethanol and distilled water to remove any trace residues of 
fatty acid adsorbed on the surface of the glass beads. Then, they dried at the ambient conditions in an oven before the treatment by the nanofluids.

\subsection{Treatment of substrates (glass or oil-wet glass bead) with the modified silica nanoparticles}

The modified silica nanoparticles were firstly dispersed using magnetically stirred and then homogenized with the aid of ultrasonic agitation for $30 \mathrm{~min}$. The prepared substrates (glass beads or oil-wet glass beads) were immersed in the nanofluid at room conditions. One important challenge is the retention of the modified nanoparticles by gravity. To overcome this problem, the nanofluid was stirred smoothly (60 rpm) during the treatment. In the experiment, irregular compact packing of glass beads was prepared in a $25 \mathrm{~mL}$ beaker. The porosity is exactly $26 \%$ due to the equal size of glass beads (Mader-Arndt et al. 2014). Eventually, the treated substrates (glass beads or oil-wet glass beads) with the modified silica nanoparticles were washed by the distilled water and dried at ambient conditions in an oven. It

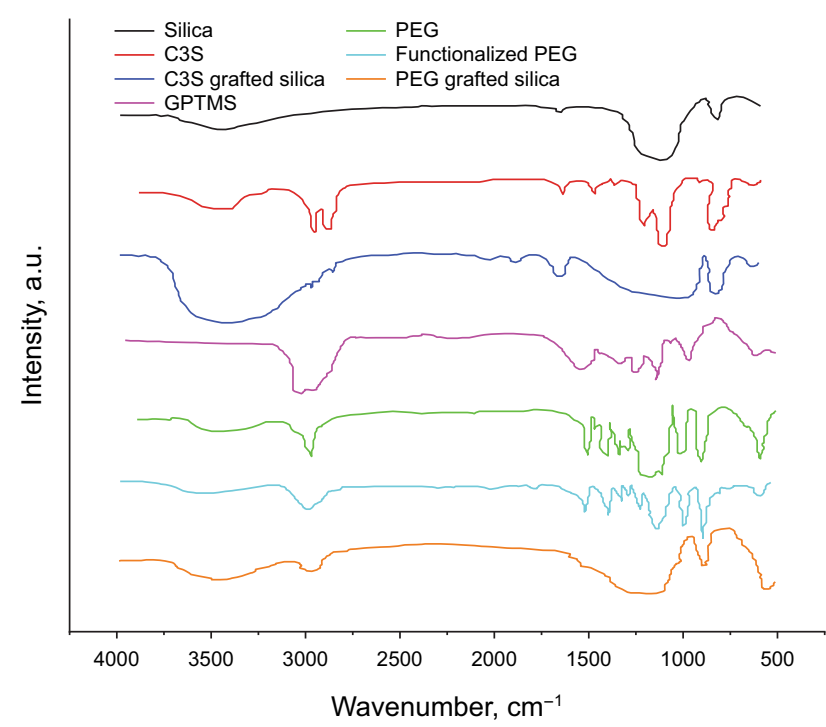

Fig. 3 FT-IR spectra of silica, trimethoxy (propyl) silane (C3S), and C3S-grafted silica. 3-glycidoxypropyltrimethoxysilane (GPTMS), polyethylene glycol methyl ether Mn 2000 (PEG1), and functionalized PEG1. 3-glycidoxypropyltrimethoxysilane (GPTMS) polyethylene glycol methyl ether Mn 5000 (PEG2), and functionalized PEG2. Silica, functionalized PEG1, and PEG1-grafted silica. Silica, functionalized PEG2, and PEG2-grafted silica

can be used for the contact angle measurement.

\subsection{Water contact angle $(\theta)$ and retention measurements}

The sessile drop technique was used to study the wettability alteration of the treated substrates using the modified nanoparticles. These experiments were carried out with $0.1-0.3$ $\mu \mathrm{L}$ distilled water droplets at two different positions on at least five glass beads. All the instruments were supported with the software image providing the ability to measure the $\theta$ averages. It is considered as the $\theta$ of the studied condition. To investigate the retention of the modified nanoparticles on substrates, the calibration curve was obtained using ultraviolet-visible (UV-VIS) spectroscopy. The UV-VIS spectra were measured by a Hash DR spectrophotometer at $400 \mathrm{~nm}$. The retention was obtained using the following equation:

$q(t)=\left(C_{i}-C_{X}\right) V \times M^{-1}$

$C_{i}$ and $C_{x}$ are initial and final concentrations of the nanofluids $(\mathrm{mg} / \mathrm{L}) . V$ is the volume of solution and $M$ is the mass of substrates. In our experiments, $V$ and $M$ were fixed at $20 \mathrm{~mL}$ and $20 \mathrm{~g}$, respectively. Finally, $q(t)$ is the amount of adsorbed modified nanoparticles on the substrates $\left(\mathrm{mg} / \mathrm{g}_{\text {glass }}\right)$.

\subsection{Characterization methods}

Fourier transform infrared spectroscopy (FT-IR) was applied to evaluate the chemical bonding between the surface of silica and polymer. FT-IR experiments were carried out by a spectrometer (VERTEX 70, Bruker Optics, Ettlingen, Germany) equipped with a deuterated triglycine sulfate (DTGS) detector. Thermogravimetric analysis (TGA) analysis was used to determine the content of polymers on the surface of the silica. The TGA patterns are obtained using the Thermogravimetric Analyzer of PerkinElmer with a heating rate of $20^{\circ} \mathrm{C} \mathrm{min}^{-1}$ in a nitrogen atmosphere from $40{ }^{\circ} \mathrm{C}$ to $800{ }^{\circ} \mathrm{C}$. Scanning electron microscope (SEM) was performed with Zeiss SEM and Oxford energy dispersive spectroscopy (EDS) to study the morphology and composition of substrates before and after treatment by the modified nanoparticles. Zeta potential analyzer (HORIBA Scientific, SZ-100z) was used to measure zeta potentials of nanofluids.

\section{Results and discussion}

\subsection{Characterizations of silica modified with polymer using FT-IR and TGA techniques}

The FT-IR spectra of silica, polymers, and polymer-coated silica are shown in Fig. 3. The peak of $887 \mathrm{~cm}^{-1}$ shows the $\mathrm{Si}-\mathrm{OH}$ group of silica (black line). In the $\mathrm{C} 3 \mathrm{~S}$ spectra (red line), there are two peaks in $798 \mathrm{~cm}^{-1}$ and $1230 \mathrm{~cm}^{-1}$ 
belonging to the $\mathrm{Si}-\mathrm{C}$ group. Also, $887 \mathrm{~cm}^{-1}$ and $1604 \mathrm{~cm}^{-1}$ peaks indicate the $\mathrm{Si}-\mathrm{OH}$ and $\mathrm{Si}-\mathrm{OC}$ groups. Peaks between 2800 and $3000 \mathrm{~cm}^{-1}$ are due to aliphatic groups of the carbon chain (Behzadi and Mohammadi 2016). In the C3Smodified silica spectra (blue line), apart from the main silica peaks, there are two peaks in $2800-3000 \mathrm{~cm}^{-1}$, which are related to C3S (Munshi et al. 2008; Richard et al. 2012). These peaks confirm the chemical reaction between C3S and silica. The FT-IR spectra of PEG functionalized with silane group (blue line) shows two peaks at $890 \mathrm{~cm}^{-1}$ and $1250 \mathrm{~cm}^{-1}$ from the GPTMS epoxy ring (purple line). Also, new peaks have appeared around $1250-1500 \mathrm{~cm}^{-1}$ and $1100 \mathrm{~cm}^{-1}$, which are related to PEG. The peak at about $1100 \mathrm{~cm}^{-1}$ belongs to the $\mathrm{Si}-\mathrm{O}-\mathrm{C}$ and $\mathrm{C}-\mathrm{O}-\mathrm{C}$ groups. As a result, polyethylene glycol methyl ether (PEG1 or PEG2) is functionalized with silane groups (Behzadi and Mohammadi 2016). As shown in Fig. 3 (brown line), after modification of the silica by PEG functionalized, a new peak appears around $2800-3000 \mathrm{~cm}^{-1}$, which is due to the binding of PEG to the silica surface.

Due to the similarity of the peaks in C3S, PEG1, and PEG2, the FT-IR technique cannot be used to study the mixed polymer grafted with silica. Therefore, TGA analysis was used to study the structure of silica modified with the mixed polymer. The ability to obtain key information

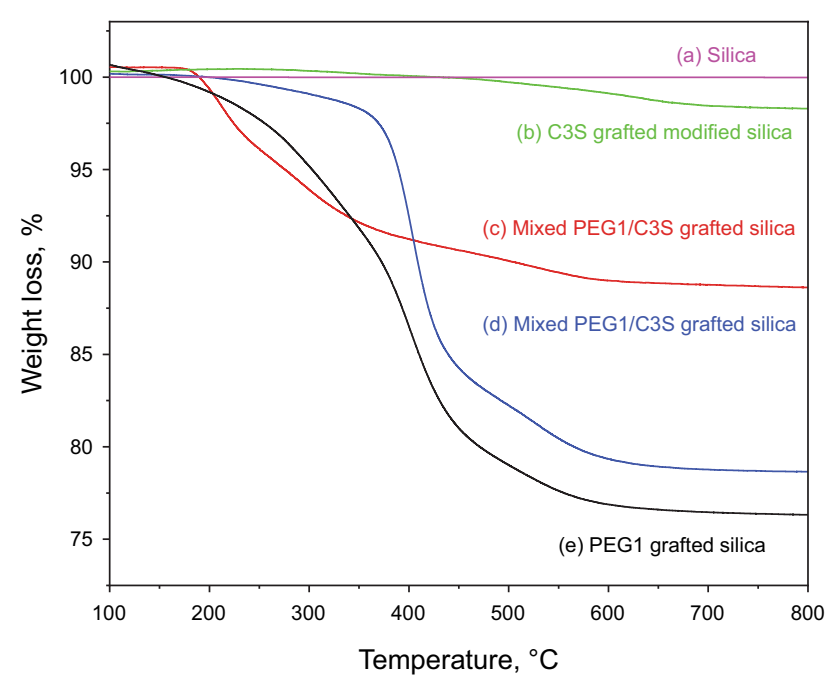

Fig. 4 TGA curves of a silica, b trimethoxy (propyl) silane (C3S)grafted silica, c mixed polyethylene glycol methyl ether $\mathrm{Mn} \sim 2000$ (PEG1)/C3S-grafted silica, $\mathbf{d}$ mixed polyethylene glycol methyl ether Mn 5000 (PEG2)/C3S-grafted silica, and e PEG1-grafted silica

about the content of polymers coupled to the surface of nanoparticles makes TGA a suitable candidate for this research (Afsharian-Moghaddam and Haddadi-Asl 2013).
The TGA curves of silica and the modified silica by the used polymers including C3S, PEG1, mixed PEG1 and C3S, and mixed PEG2 and C3S are shown in Fig. 4. It is evident from Fig. 4a, the weight of silica is constant from 100 to $800{ }^{\circ} \mathrm{C}$. According to the previous description, the modification of silica nanoparticle is based on two-step strategies. In the first step, the silica surface was modified by C3S. In the second step, the surface of the silica nanoparticles changed using $\mathrm{C} 3 \mathrm{~S}$ was modified by PEG1 or PEG2. To determine the content of polymers on the surface of the silica, TGA analysis was performed on the modified silica with $\mathrm{C} 3 \mathrm{~S}$ in the absence and presence of PEG1 and PEG2. In the TGA curve in Fig. 4b, the content of $\mathrm{C} 3 \mathrm{~S}$ was about $2 \%$. The data in Figs. $4 \mathrm{c}$ and d demonstrate that the content of PEG1 and PEG2 for the modified silica by $\mathrm{C} 3 \mathrm{~S}$ was approximately $11 \%$ and $21 \%$, respectively. Besides, the content of PEG1 coating on the silica nanoparticles is estimated at $23 \%$ (Fig. 4 e) which is more than those of the other silica nanoparticles modified with PEG1/C3S and PEG2/C3S. For modified silica by PEG1/ $\mathrm{C} 3 \mathrm{~S}$ due to the presence of $\mathrm{C} 3 \mathrm{~S}$ on nanoparticle surface at the first step of modification, there is a decrease in polymers content in comparison with modified silica by PEG1. The presence of C3S on the silica surface causes increasing steric effects which decreases the content of PEG1 on the surface of the silica. In the case of the modified silica with PGE2/C3S, the content of the polymer is more than modified silica with C3S/PGE1 but is nearly similar to the modified silica by PEG1. This fact is due to the more molecular weight of PEG2 in comparison with PEG1 making the content of PEG2 on the surface of modified silica with $\mathrm{C} 3 \mathrm{~S}$ was close to the modified silica by PEG1. As a result, for the modified silica by all the mentioned materials, the content of polymers was less than $\sim 25 \%$. The relatively low content of polymers on the surface of silica is due to the grafted to method that applied for their synthesis. As it can be observed, this method causes lower absolute grafting ratios of polymers in comparison with grafted from the method. This fact is due to the mechanism of the steric effect of polymer chains (Iglauer et al. 2009).

\subsection{Characterizations of substrates by SEM, EDS, and contact angle measurement}

Figure $5 \mathrm{a}-\mathrm{c}$ represents SEM, EDS, and $\theta$ of the glass bead, the treated glass bead by piranha solution, and the oil-wet glass bead (modified by palmitic acid), respectively. Piranha treatment decreased the $\theta$ of the glass bead from $62^{\circ}$ to $7^{\circ}$ (Fig. 5a1 and b1). After modification with a fatty acid, the $\theta$ of glass bead increased to $114^{\circ}$ (Fig. $5 \mathrm{c}_{1}$ ).

Figure 5 shows the results obtained from EDS measurements of the glass bead. The treated glass bead by piranha 


\section{(a) Glass bead}
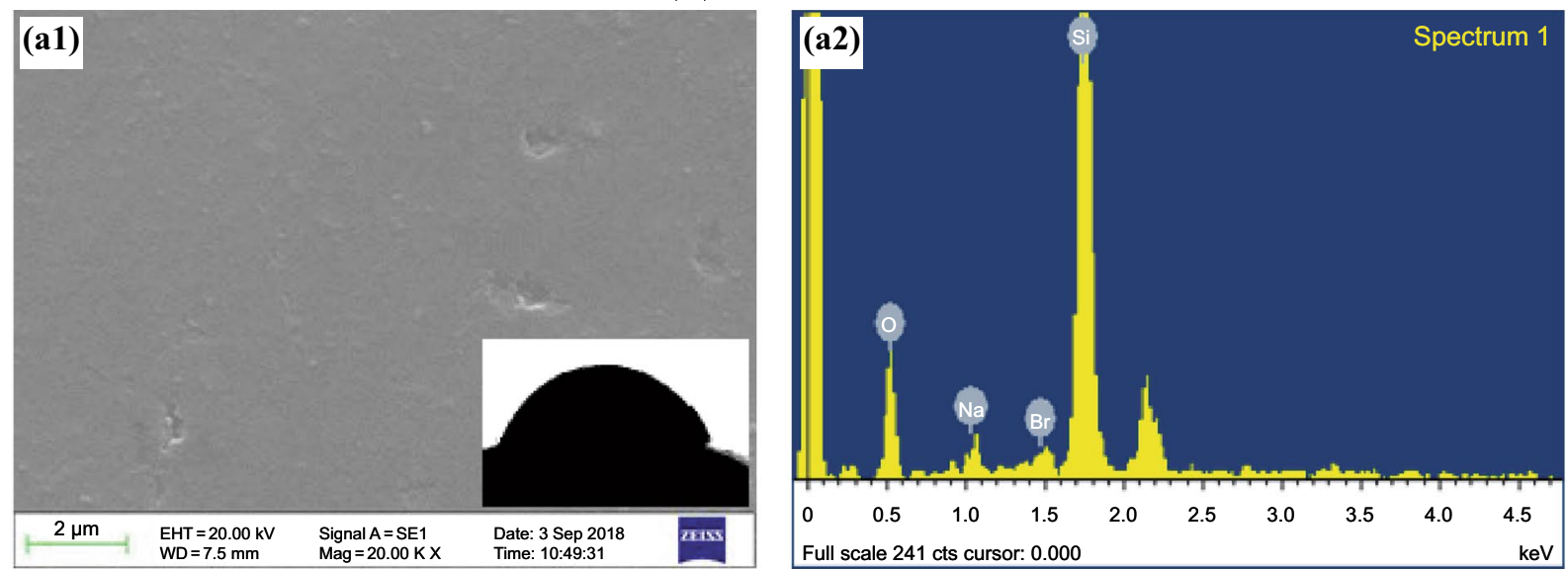

(b) Treated glass bead by piranha solution
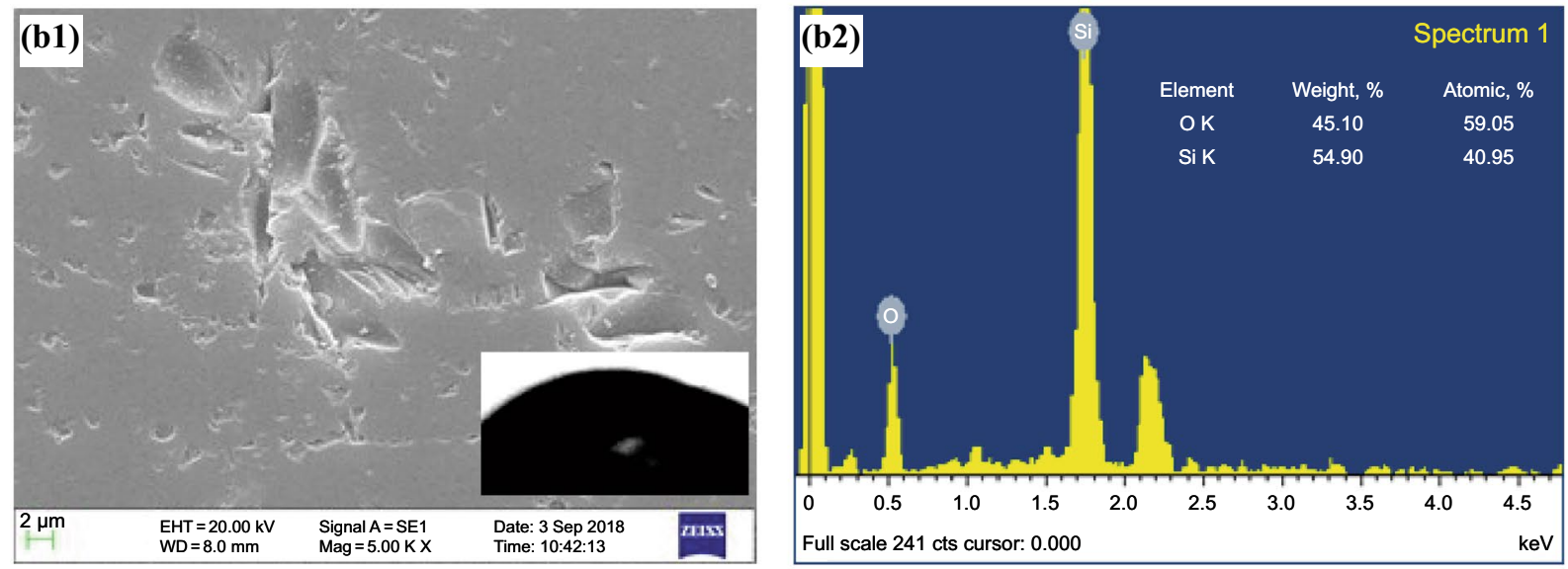

(c) Oil-wet glass bead (modified glass bead by palmitic acid)
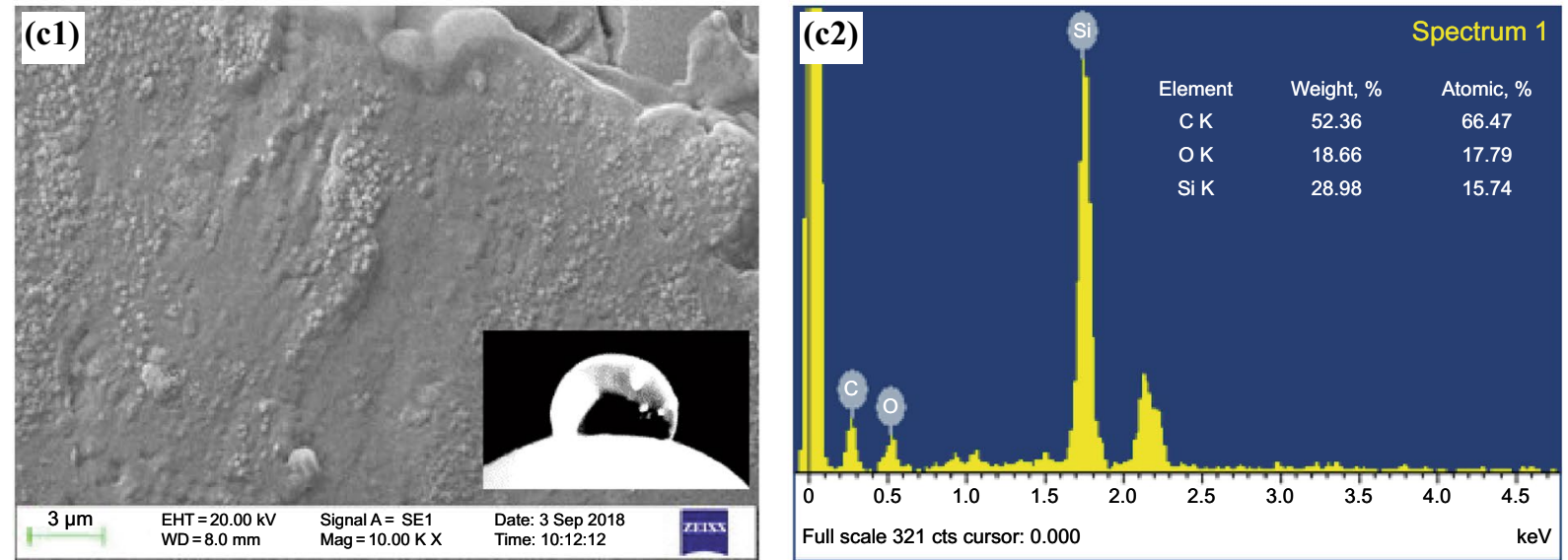

Fig. 5 SEM, EDS, and water contact angle $(\theta)$ of a surface of the glass, $\mathbf{b}$ treated glass bead by piranha solution, and $\mathbf{c}$ oil-wet glass bead

solution and oil-wet glass bead (modified by palmitic acid) are respectively shown in Fig. 5a2, b2, and c2. Based on the obtained EDS results, the amount of available carbon on the surface of the modified glass bead by palmitic acid (oil-wet glass bead) is $52.36 \%$ indicating palmitic acid is vastly adsorbed on the surface of the glass bead. To investigate the retention of polymer and mixed polymer grafted 

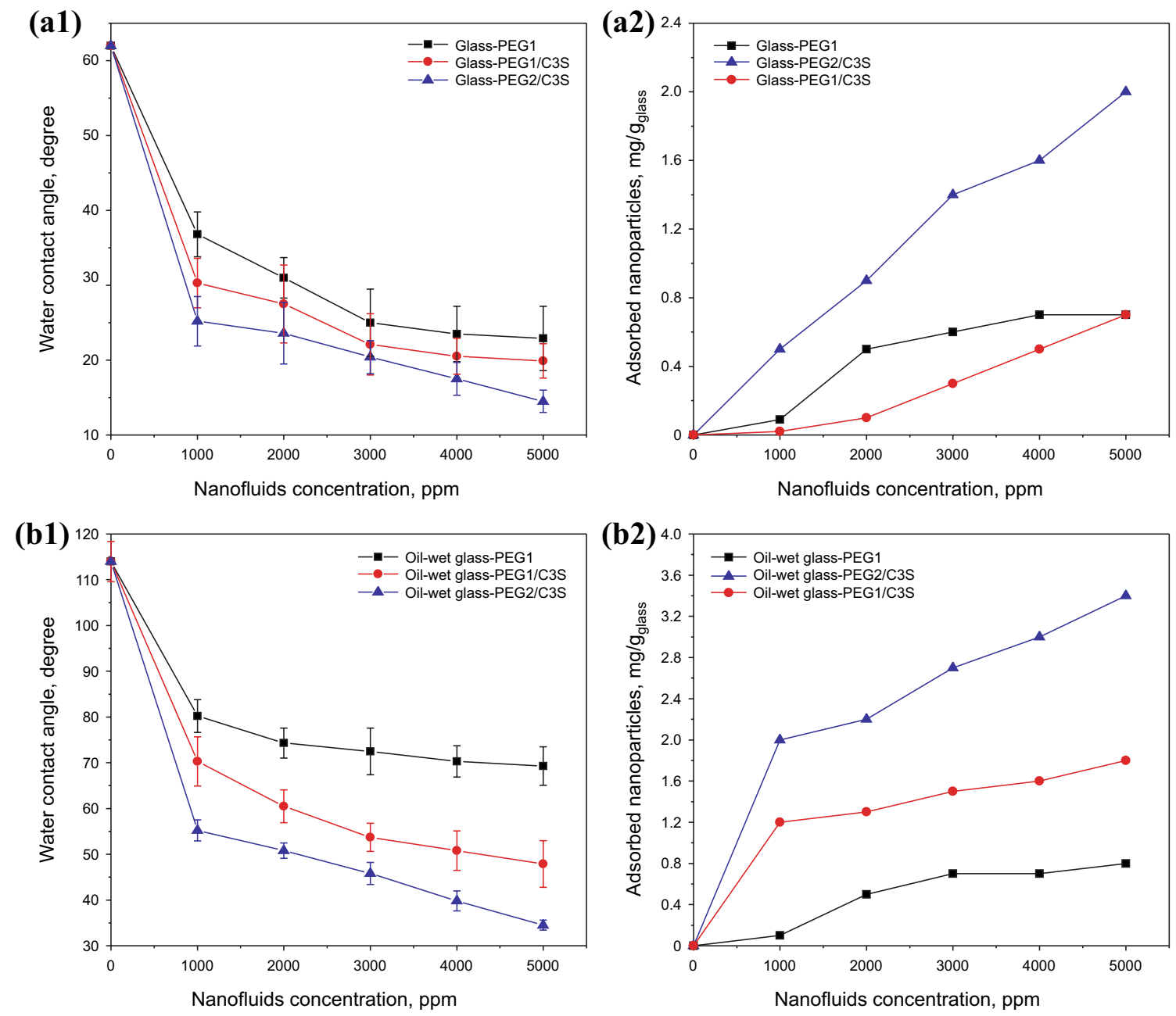

Fig. 6 Effect of modified nanofluids concentrations in $2 \mathrm{~h}$ exposure time on a1 water contact angle $(\theta)$ and $\mathbf{a} 2$ retention for the glass bead substrate. Effect of modified nanofluids concentrations in $2 \mathrm{~h}$ exposure time on $\mathbf{b} \mathbf{1} \theta$ and $\mathbf{b} \mathbf{2}$ retention for the oil-wet glass bead substrate (polyethylene glycol methyl ether Mn 2000 (PEG1), mixed PEG1/trimethoxy (propyl) silane (C3S)-grafted silica, and mixed polyethylene glycol methyl ether $\mathrm{Mn} \sim 5000$ (PEG2)/C3S grafted silica)

with silica nanoparticles, the glass bead, and the oil-wet glass bead was used as substrates.

\subsection{Effect of nanofluids concentrations}

To obtain appropriate performance, different interrelated parameters were taken into account on the wetting and retention of substrates. Since the nanoparticles influence wetting and retention of substrates, the choice of suitable concentration is very significant in the EOR procedure. Choose a proper concentration is restricted by various features which are essential for the proper effect of nanoparticles. The high concentration of nanoparticles $(>20,000 \mathrm{ppm})$ may reduce the reservoir permeability ( $\mathrm{Ju}$ et al. 2006; Roustaei and Bagherzadeh 2015) because the stability of nanoparticle suspension reduces dramatically by increasing their concentration (Al-Anssari et al. 2017a; Rubio et al. 2017). Moreover, economic costs must be minimized for using nanofluid (AlAnssari et al. 2016).

Please note to this point that PEG1, PEG1/C3S, and PEG2/C3S are referred to as the modified silica nanoparticle by PEG1, the modified silica nanoparticle by PEG1 and $\mathrm{C} 3 \mathrm{~S}$, and the modified silica nanoparticle by PEG2 and C3S. Figure 6 shows the effect of the nanofluids concentrations in $2 \mathrm{~h}$ treatment on the wettability and retention of the glass bead and the oil-wet glass bead, respectively. In Fig. 6 a1, the initial $\theta$ of glass bead is $62^{\circ}$. As can be seen in Table 1 , the results revealed that the lowest concentration of the modified nanoparticle with the most increase in the decrease of $\theta$ for the glass bead is $3000 \mathrm{ppm}$ belonging to PEG1 and PEG1/ C3S. Therefore, $3000 \mathrm{ppm}$ can be considered as optimum concentration for PEG1 and PEG1/C3S. In this concentration, the $\theta$ of the glass bead is decreased to $25^{\circ}$ and $22^{\circ}$ for PEG1 and PEG1/C3S, respectively. In contrast to PEG1 


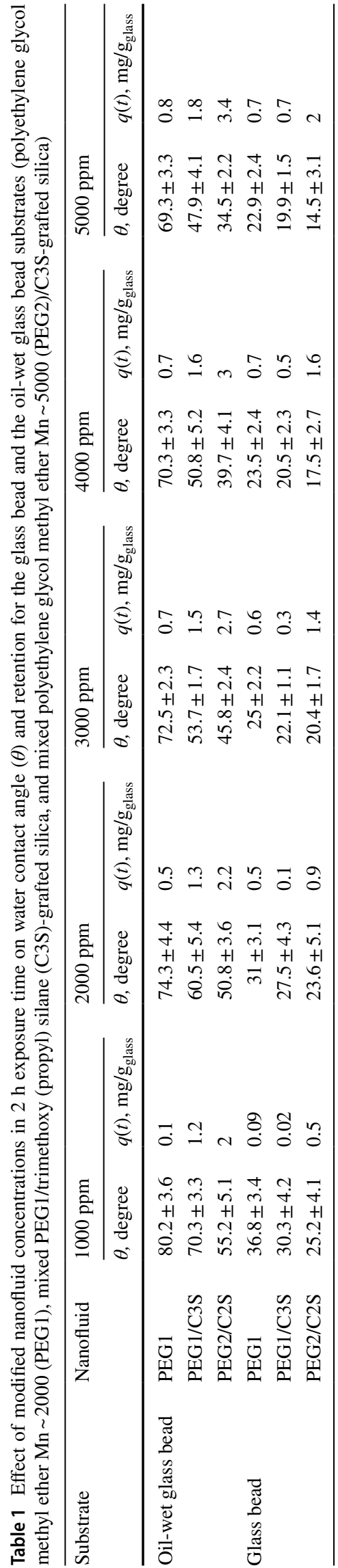

and PEG1/C3S, the $\theta$ of substrates for PEG2/C3S has linear behavior by increasing the concentration of nanofluid. The lowest concentration of this nanofluid with the highest efficiency on the $\theta$ reduction (from $62^{\circ}$ to $24^{\circ}$ ) is at $1000 \mathrm{ppm}$.

As it is shown in Fig. 6 a2, the retention of the PEG2 onto the glass bead was more than PEG1 and PEG1/C3S. This fact is due to the higher molecular weight of this nanofluid. The major energy for retention is based on the entropy gain associated with the desorption of serval water molecules for each adsorbed polymer molecule and this energy can be enhanced by increasing the molecular weight of the polyethylene glycol (Parfitt and Greenland 1970). In Fig. 6b1, PEG1 changed the oil-wet state of the glass bead (initial $\left.\theta=114^{\circ}\right)$ to an intermediate-wet state $\left(\theta=72^{\circ}\right)$ at $3000 \mathrm{ppm}$. PEG2/C3S and PEG1/C3S had a better performance which changed the oil-wet glass bead to a strongly water-wet state $\left(\theta=55^{\circ}\right.$ for PEG $2 / \mathrm{C} 3 \mathrm{~S}$ and $\theta=54^{\circ}$ for PEG1/C3S $)$ at 1000 and $3000 \mathrm{ppm}$, respectively. By changing substrates from water-wet state to oil-wet state, the amount of retention remained almost constant for PEG1 while increased for PEG1/C3S and PEG2/C3S (Fig. 6b2). For instance, in oilwet substrates, the retention of PEG1/C3S (3000 ppm) and PEG2/C3S (1000 ppm) were increased by $67 \%$ and $80 \%$, respectively. It is a possibility because of the hydrophobic interaction between $\mathrm{C} 3 \mathrm{~S}$ of the modified silica with the fatty acid of the glass bead which caused more efficiency of PEG1/C3S and PEG2/C3S (Fig. 7). This trend is similar to protein retention (Rabe et al. 2011).

The results demonstrate that increase in the nanofluid concentrations had a significant effect on the $\theta$ reduction. It is consistent with previous studies about the silica nanoparticle concentrations on the calcite and the glass bead substrates (Al-Anssari et al. 2016; Nikolov et al. 2010; Rostami et al. 2011) and retention of the modified silica by polyethylene glycol onto the clay minerals (Omurlu et al. 2016). Furthermore, it can be concluded that when the hydrophobicity of the substrates is increased, the retention of the mixed polymer coating on the silica nanoparticles is also enhanced. Most reservoir rocks are strongly oil-wet, and this wettability state not only reduces the retention of the mixed polymer coating on the silica nanoparticles but also it can increase the retention of these nanofluids due to the increase in hydrophobic interaction.

\subsection{Effect of exposure time}

The exposure time of the substrates into the nanofluids is one of the key factors in the retention of material into the substrates (Al-Anssari et al. 2017a). Hence, the selection of a suitable time is necessary because an increase in the time makes substrates reach their maximum retention capacity (Roustaei and Bagherzadeh 2015). It was found that the most efficient nanofluid concentrations for the $\theta$ reduction of the 
(a)

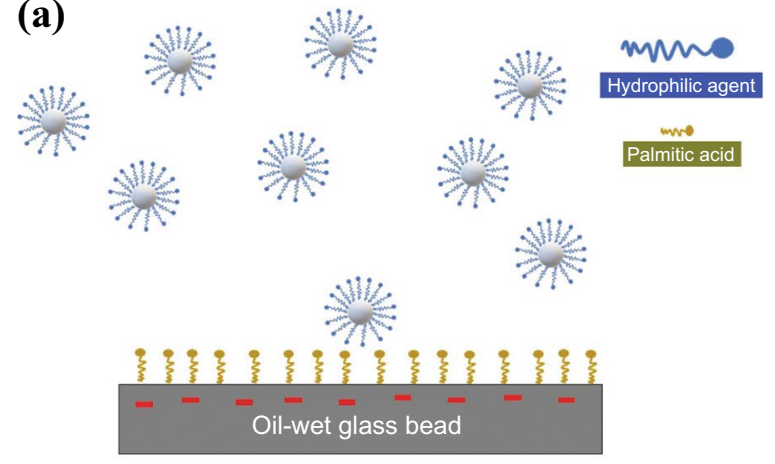

(b)

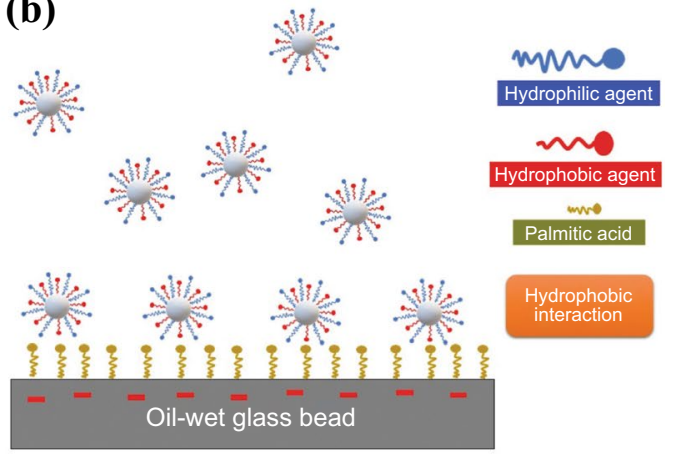

Fig. 7 Schematic of retention for $\mathbf{a}$ The polymer-coated silica nanoparticles and $\mathbf{b}$ The mixed polymer-coated silica nanoparticles
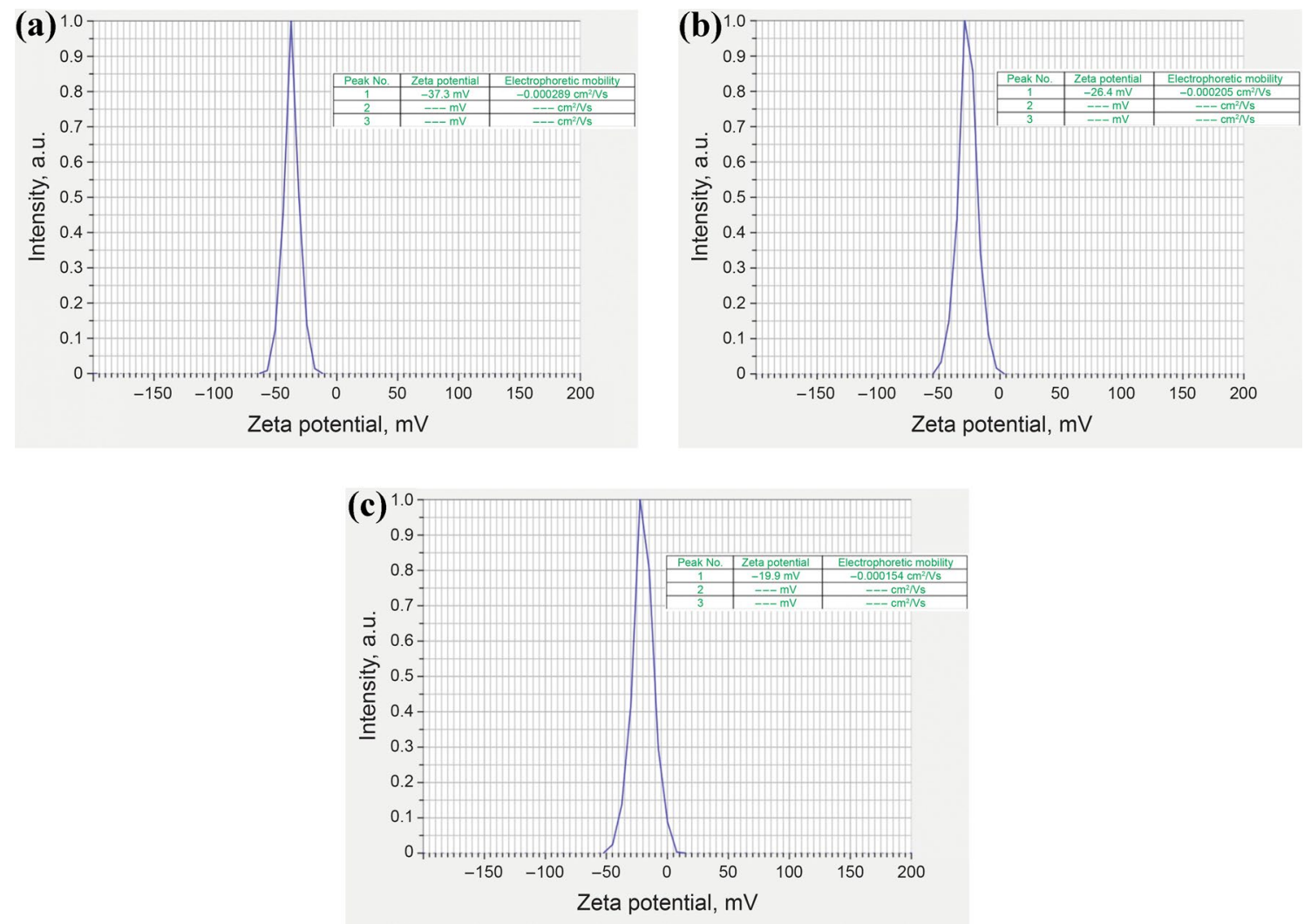

Fig. 8 Zeta potential of modified nanoparticles for the treatment of glass bead and oil-wet glass bead substrates. a polyethylene glycol methyl ether Mn 5000 (PEG2)/trimethoxy (propyl) silane (C3S)-1000 ppm, b PEG1-3000 ppm, and c polyethylene glycol methyl ether Mn 2000 (PEG1)/C3S-3000 ppm

substrates is 3000 ppm for PEG1 and PEG1/C3S and also 1000 ppm for PEG2/C3S. Therefore, these concentrations were selected to study the effect of time on the retention of the substrates.

Figure 8 shows the zeta potential of nanofluids. The zeta potentials for PEG1 (3000 ppm), PEG1/C3S (3000 ppm), and PEG2/C3S (1000 ppm) were obtained to be $-26,-20$, and $-37 \mathrm{mV}$, respectively. Zeta potential is related to the colloidal stability of the nanofluid and the low zeta potential shows that the nanofluid is unstable (Qi et al. 2018; Zhu et al. 2016). Recent studies indicated that the zeta potential higher than the absolute value of $25 \mathrm{mV}$ can stabilize nanofluid (Mondragon et al. 2012).

To explore what way exposure time of the modified nanoparticles may affect the wettability alteration and retention of the glass bead and oil-wet glass bead substrates, $\theta$ and 

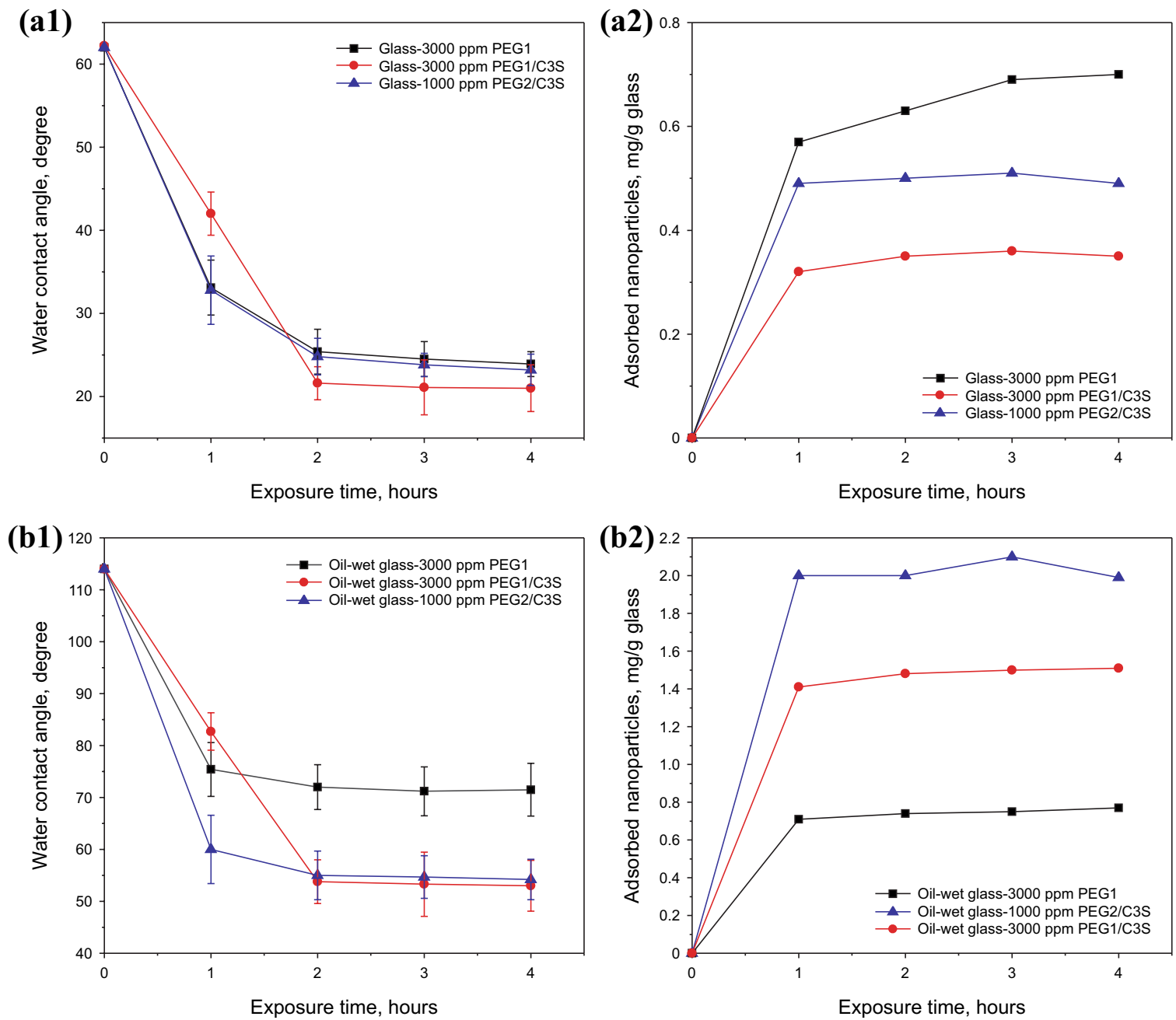

Fig. 9 Effect of modified nanofluids exposure time on a1 water contact angle $(\theta)$ and a2 retention of the glass bead substrate. Effect of modified nanofluids exposure time on $\mathbf{b} 1 \theta$ and $\mathbf{b 2}$ retention of the oil-wet glass bead substrate (3000 ppm polyethylene glycol methyl ether Mn 2000 (PEG1), $3000 \mathrm{ppm}$ mixed PEG1/trimethoxy (propyl) silane (C3S)-grafted silica, and $1000 \mathrm{ppm}$ mixed polyethylene glycol methyl ether $\mathrm{Mn} \sim 5000$ (PEG2)/C3S-grafted silica)

retention are recorded vs. exposure time (Fig. 9). The results in Fig. 9a1 and a2 are for the glass bead substrates. As it is observed from Fig. 9 a1, $\theta$ of all treatments with PEG1, PEG1/C3S, and PEG2/C3S was rapidly decreased to $2 \mathrm{~h}$ and then reached a stable value. Also, Fig. 9a1 shows that retention of all treatments with PEG1, PEG1/C3S, and PEG2/ $\mathrm{C} 3 \mathrm{~S}$ was sharply increased with exposure time up to $1 \mathrm{~h}$ and then remain constant for PEG1 and PEG2/C3S. However, there are very few changes $\theta$ in for PEG1/C3S. This is since the substrates reach their retention capacity and irreversible retention (Fig. 9a2). The results in Fig. 9b1 and b2 are for the oil-wet glass bead substrates. Figure $9 \mathrm{~b} 1$ shows that $\theta$ was rapidly decreased to $1 \mathrm{~h}$ for PEG1 and PEG2/C3S treatments while decreased in $2 \mathrm{~h}$ for PEG1/C3S treatment. Figure $9 \mathrm{~b} 2$ shows that the amount of retention increased sharply to around $1 \mathrm{~h}$ and then remains constant for all of the nanofluid treatments. By comparing the zeta potential of the nanofluids, it can be concluded that the lowest zeta potential of PEG1/C3S nanofluid $(-20 \mathrm{mV})$ decreased the retention rate of PEG1/C3S on glass bead and oil-wet glass bead substrates.

The morphology, composition, and $\theta$ of the glass bead and the oil-wet glass bead substrates treatment by the nanofluids in $2 \mathrm{~h}$ of exposure time is shown in Figs. 10 and 11. Figure 10a-c shows treated glass beads by PEG1, PEG1/C3S, and PEG2/C3S, respectively. In the treated glass bead by PEG1 and PEG1/C3S, adsorbed modified nanoparticles have heterogeneous distribution due to the agglomeration in the retention process (Fig. 10a1 and b1). On the other hand, in the treated glass bead by PEG2/C3S, the adsorbed modified nanoparticle has homogeneous distribution due to the highest zeta potential (Fig. 10c1). In 
(a) Glass bead in $2 \mathrm{~h}$ treatment with PEG1
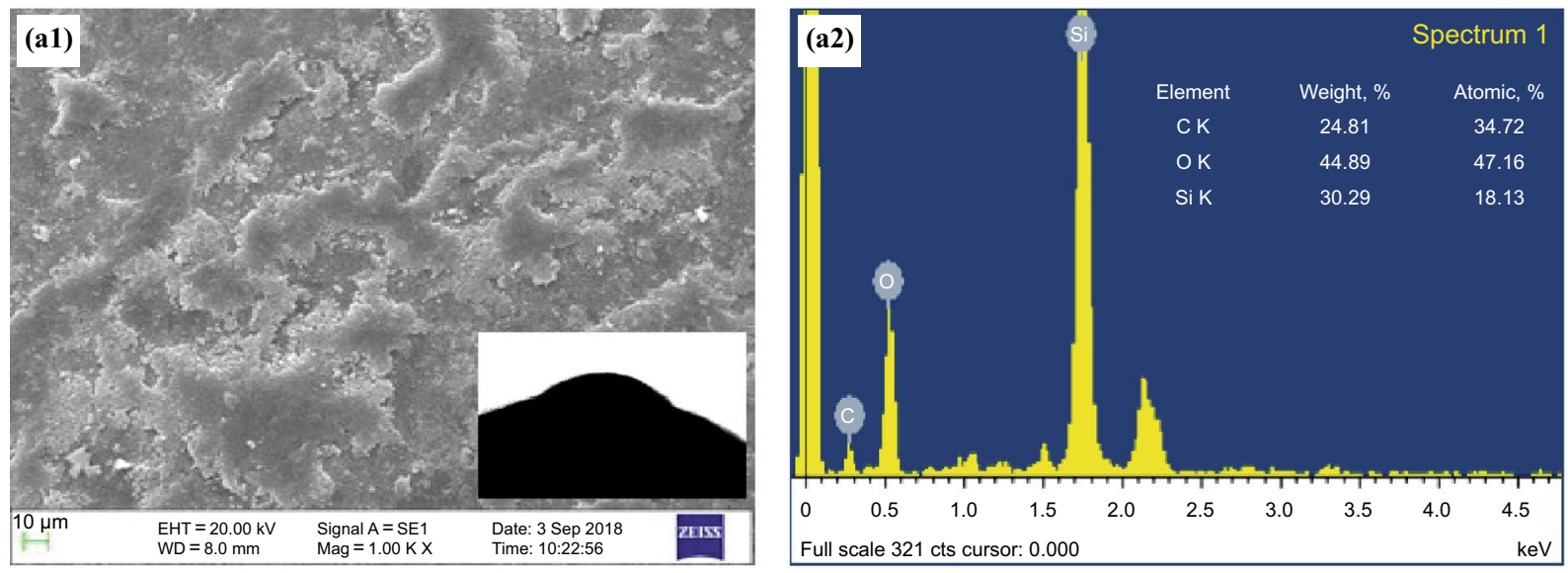

(b) Glass bead in $2 \mathrm{~h}$ treatment with PEG1/C3S
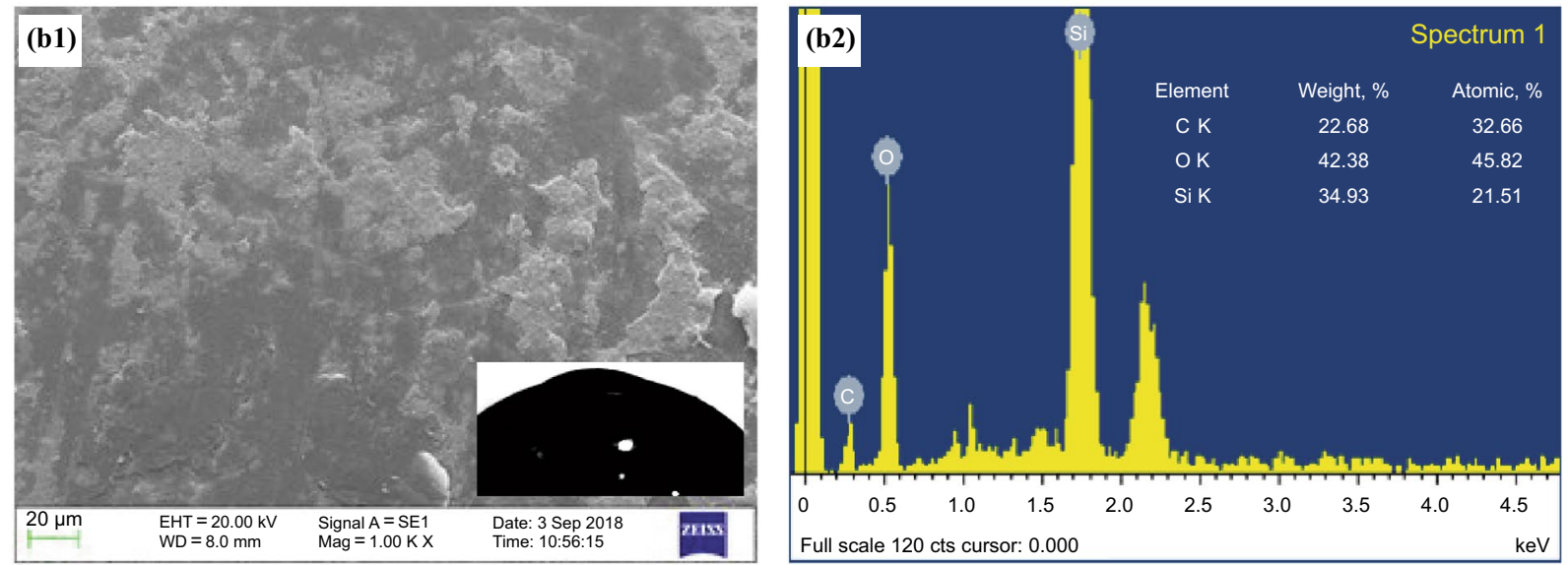

(c) Glass bead in $2 \mathrm{~h}$ treatment with PEG2/C3S
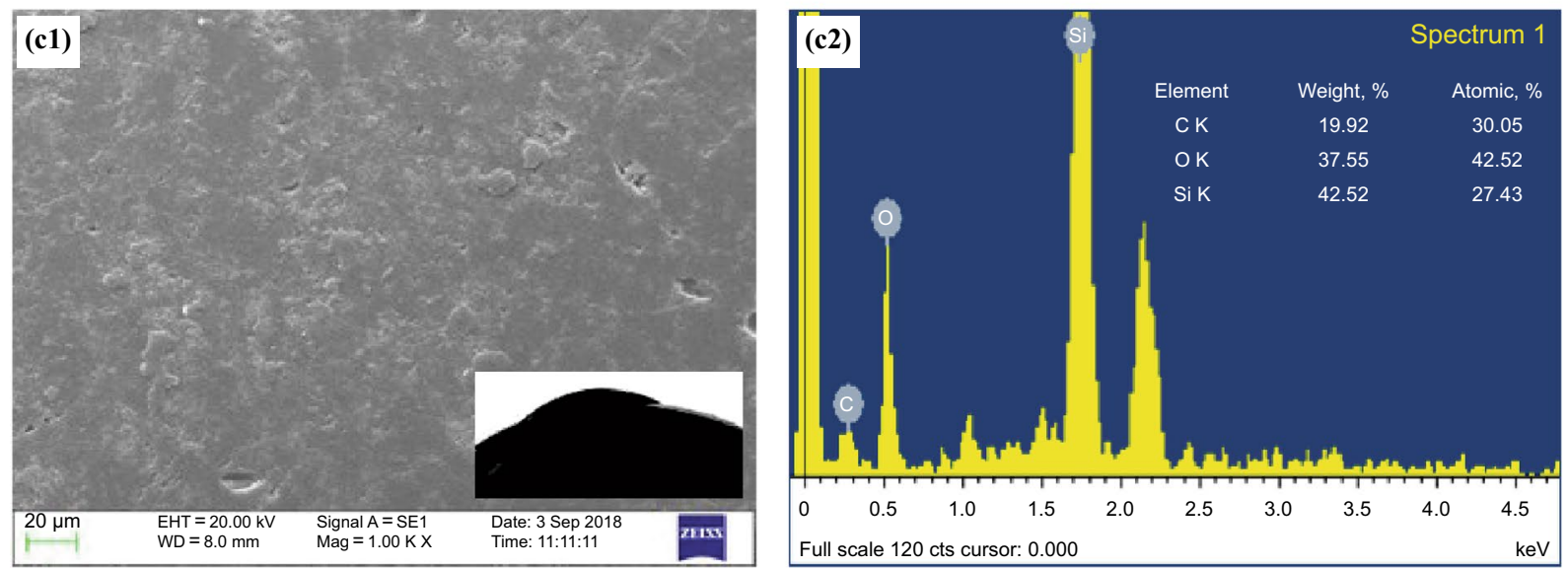

Fig. 10 SEM, EDS, and water contact angle $(\theta)$ of treated glass bead substrate in $2 \mathrm{~h}$ exposure time by a 3000 ppm polyethylene glycol methyl ether Mn 2000 (PEG1). b 3000 ppm mixed PEG1/trimethoxy (propyl) silane (C3S)-grafted silica, and c 1000 ppm mixed polyethylene glycol methyl ether Mn 5000 (PEG2)/C3S-grafted silica

Fig. 10a2, b2, and c2, the amount of available carbon on the surface of glass bead substrates were obtained to be $24.81 \%, 22.68 \%$, and $19.92 \%$ for PEG1, PEG1/C3S, and
PEG2/C3S, respectively, which indicates that modified nanoparticles are adsorbed. 
(a) Oil-wet glass in $2 \mathrm{~h}$ treatment with PEG1
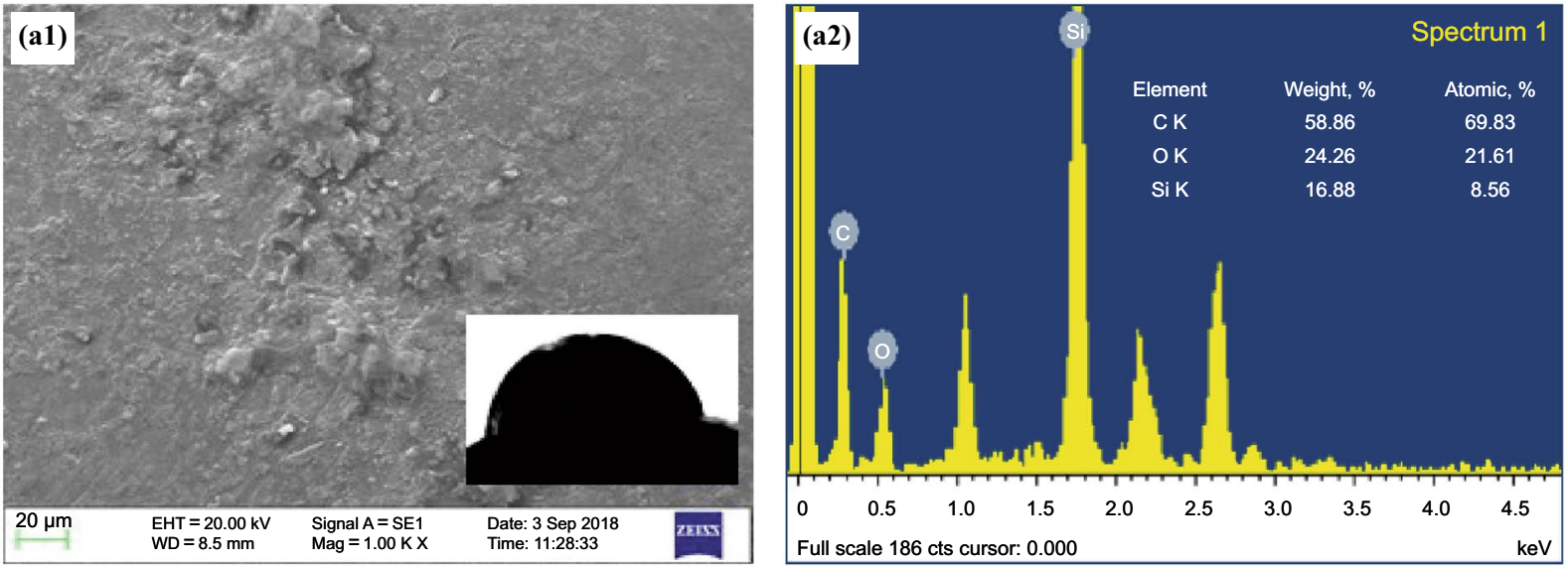

(b) Oil-wet glass in $2 \mathrm{~h}$ treatment with PEG1/C3S
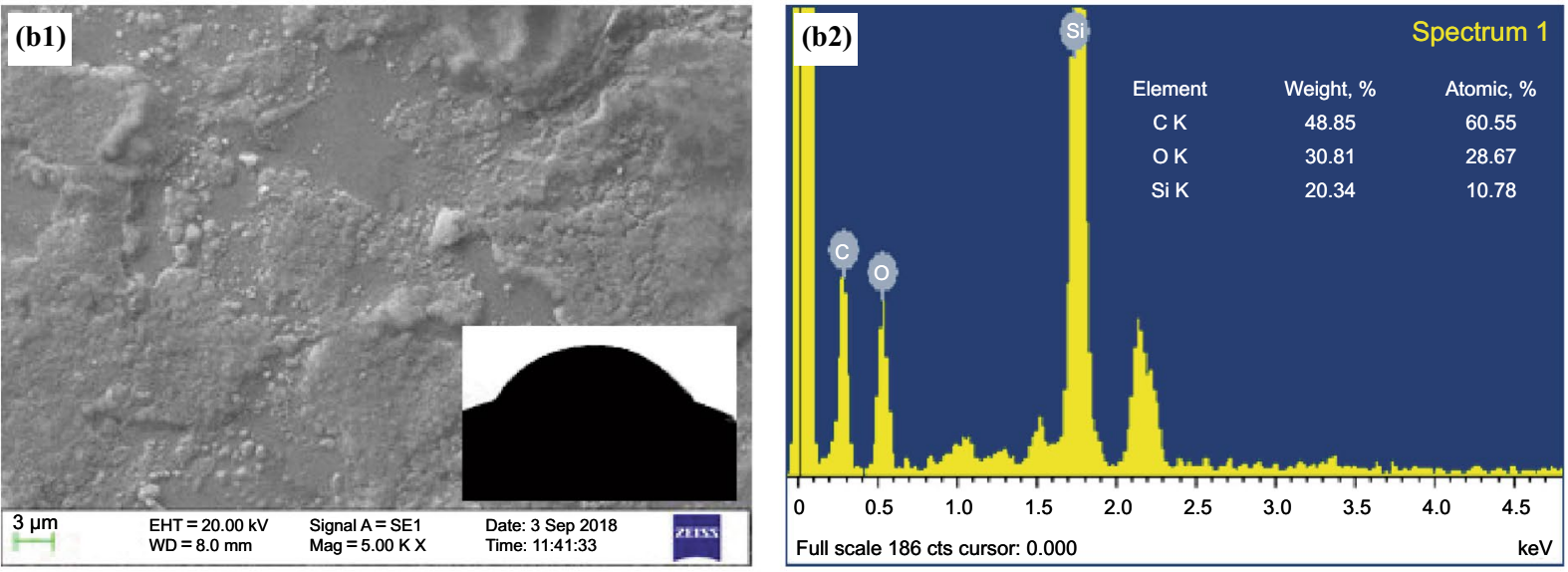

(c) Oil-wet glass bead in $2 \mathrm{~h}$ treatment with PEG2/C3S
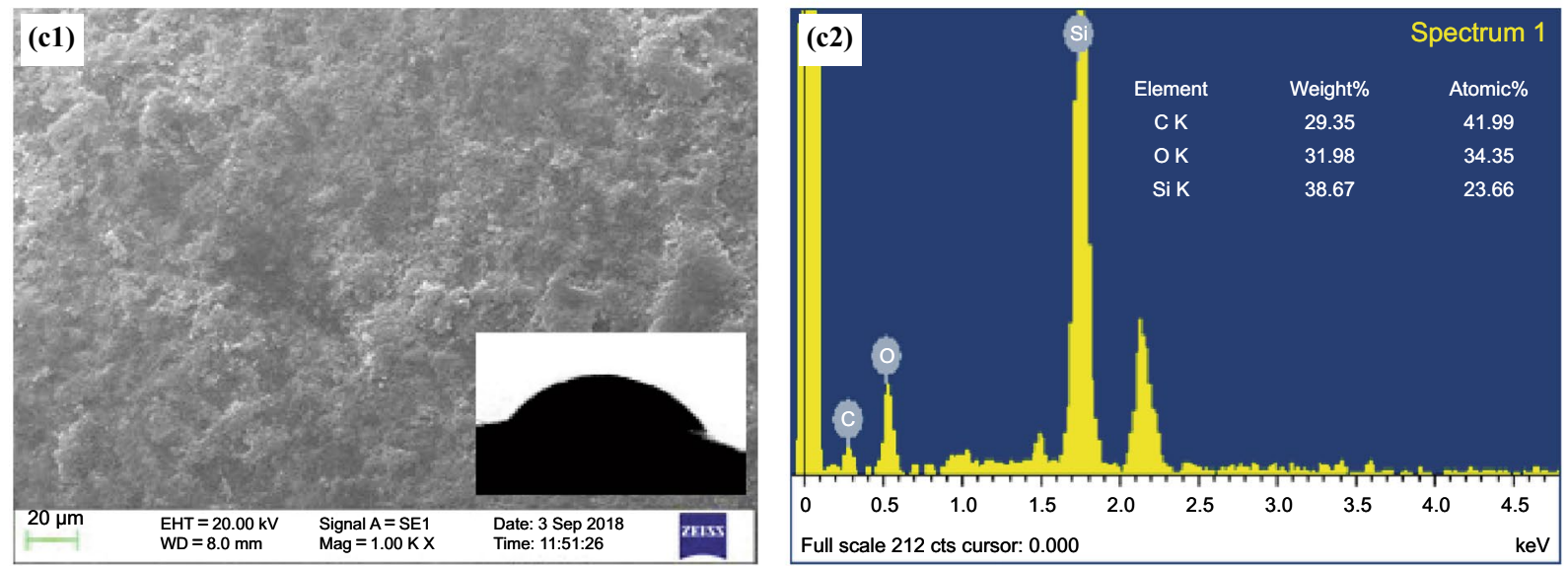

Fig. 11 SEM, EDS, and water contact angle $(\theta)$ of treated oil-wet glass bead substrate in $2 \mathrm{~h}$ exposure time by a 3000 ppm polyethylene glycol methyl ether Mn 2000 (PEG1) b 3000 ppm mixed PEG1/trimethoxy (propyl) silane (C3S)-grafted silica, and c 1000 ppm mixed polyethylene glycol methyl ether Mn 5000 (PEG2)/C3S-grafted silica

As a result, the more colloidal stability of the modified nanoparticles causes an increase in the retention rate. Also, it can affect the more uniform retention of the modified nanoparticles on the substrates. Homogeneous retention distribution of the nanoparticles has a great impact on the process of EOR. For better extraction of the oil from the 

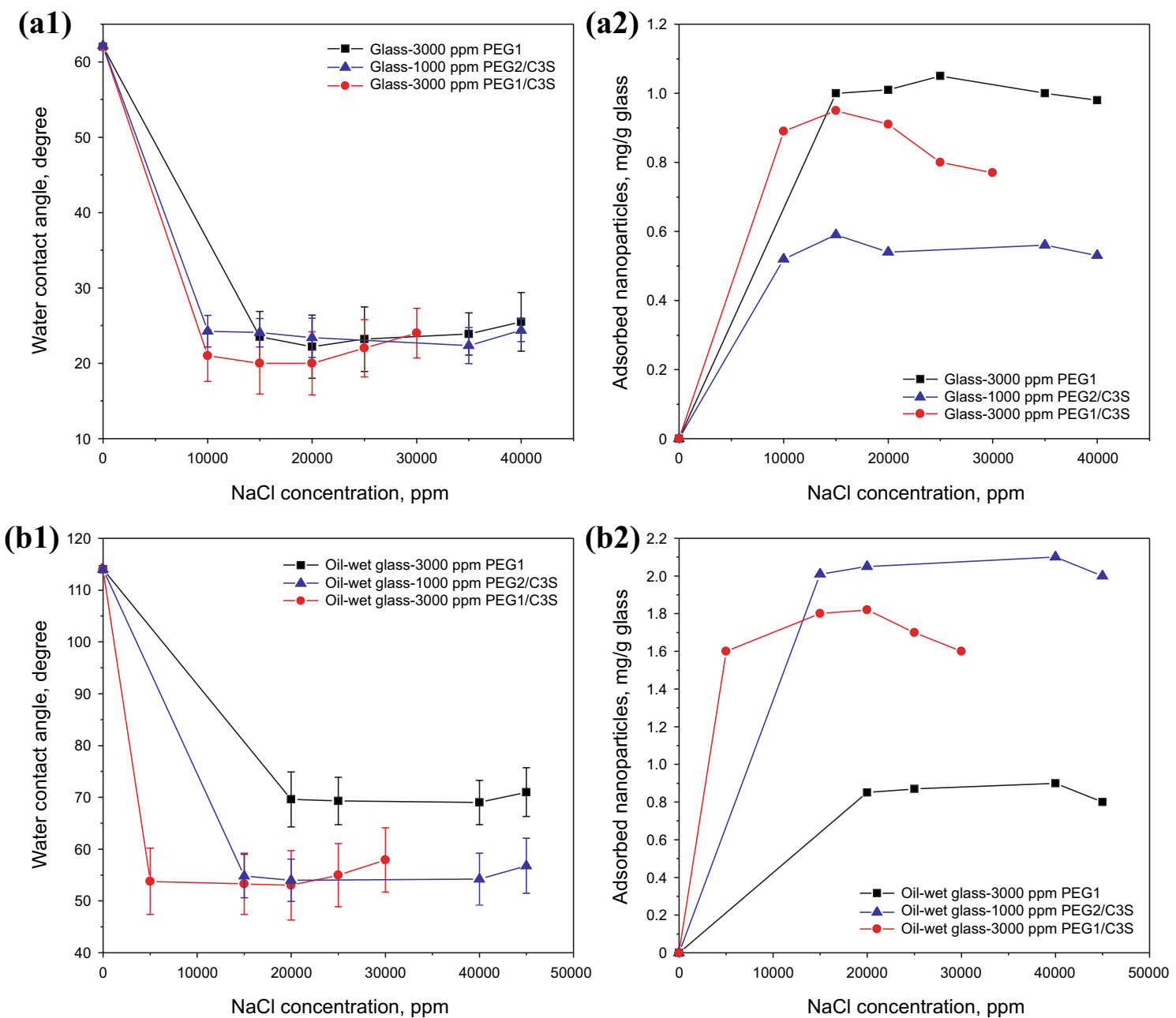

Fig. 12 Effect of $\mathrm{NaCl}$ concentrations in $2 \mathrm{~h}$ exposure time on $\mathbf{a} 1$ water contact angle $(\theta)$ and $\mathbf{a} 2$ retention of the glass bead substrate. Effect of $\mathrm{NaCl}$ concentrations in $2 \mathrm{~h}$ exposure on $\mathbf{b 1} \theta$ and $\mathbf{b 2}$ retention of the oil-wet glass bead substrate (3000 ppm polyethylene glycol methyl ether Mn 2000 (PEG1), 3000 ppm mixed PEG1/trimethoxy (propyl) silane (C3S)-grafted silica, and 1000 ppm mixed polyethylene glycol methyl ether $\mathrm{Mn} \sim 5000$ (PEG2)/C3S-grafted silica)

reservoirs, nanoparticles need to be uniformly adsorbed on the rocks. The high colloidal stability of the silica nanoparticles modified with mixed polymer (PEG2/C3S) enables this nanofluid to be uniformly adsorbed on the substrate.

\subsection{Effect of salinity}

It is well-known that the retention of modified nanoparticles is responsible for the wettability alteration of the glass bead and the oil-wet glass bead substrates. The salinity of the oil reservoirs has a direct impact on the stability of injected nanofluids and the retention of the nanoparticles on the reservoir rock. A major factor to stabilize the nanoparticle in suspension is the repulsive forces between the nanoparticles. It is found in this research that some of the salts not only reduce repulsion forces but also cause agglomeration and precipitation of nanofluid (McElfresh et al. 2012). However, interestingly, high salinity makes the oil-wet rock to be more water-wet due to the increase in the physicochemical interactions (Hendraningrat 2015).

According to Fig. 12, when the $\mathrm{NaCl}$ concentration is increased, $\theta$ is decreased for all of the substrates (glass beads or oil-wet glass beads). This may be related to the enhanced retention of the modified nanoparticles on the substrates. An increase in the $\mathrm{NaCl}$ concentration can improve the retention and $\theta$ reduction of the substrates. This fact is due to the decrease of the negative charges between the glass bead and the modified nanoparticles (Al-Anssari et al. 2016). On the other hand, at a high concentration of $\mathrm{NaCl}$, the repulsive force between the modified nanoparticles as well as between the modified nanoparticles and the substrates is attenuated. It is strong evidence for increasing the agglomeration and precipitation of the modified nanoparticles which reduces the retention and $\theta$ reduction. As can be seen, from Table 2 , 


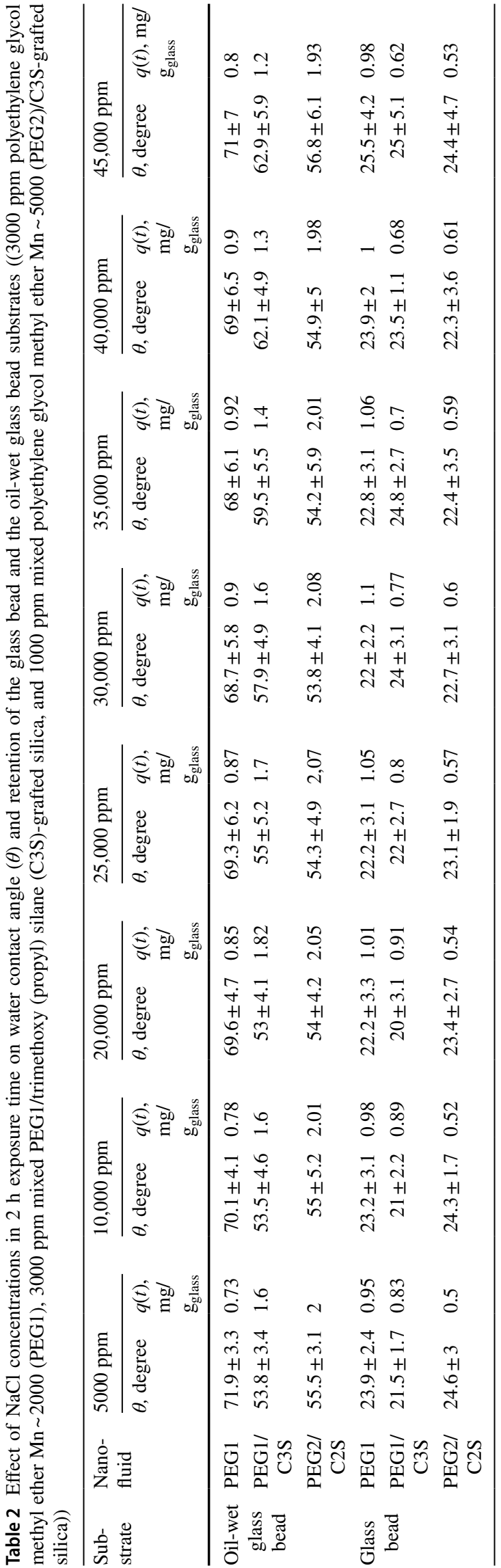

for the treatment of glass bead substrates by PEG1/C3S, $\theta$ is decreased from $22^{\circ}$ to $20^{\circ}$ along with an increase of $\mathrm{NaCl}$ concentration to $20,000 \mathrm{ppm}$. After this point, $\theta$ was increased to $24^{\circ}$ at a concentration of 40,000 ppm.

Furthermore, there is an optimal range for $\mathrm{NaCl}$ concentration to reduce the $\theta$ of the substrates. Thus, the obtained results could be compared to the previous studies for the treatment of the calcite by the silica nanofluid (AlAnssari et al. 2016) and surfactant with similar formulations, showing a good correlation with the same behavior (Iglauer et al. 2009; Salager et al. 2000).

Figures 13 and 14 show the morphology and composition of the treated glass bead as well as the oil-wet glass bead substrates by the modified nanoparticles in the $\mathrm{NaCl}$ concentration of $20,000 \mathrm{ppm}$. Figure 13a, b, and c shows treated glass beads by PEG1, PEG1/C3S, and PEG2/C3S, respectively. Salinity has a remarkable effect on the morphology of the glass bead surfaces in comparison with the other morphology of surfaces in the previous section (Fig. 10a-c). As shown in Fig. 13a and b, the surface indicates cubic like structure which available $\mathrm{Cl}$ was $22.61 \%$ and 49.73\% for PEG1 and PEG1/C3S, respectively. It indicates sodium chloride is present on the glass bead surfaces. The retention of PEG1 and PEG1/C3S in the presence of salt has been increased to $40 \%$ and $63 \%$, respectively. In the presence of salinity on the glass bead substrate, the retention of PEG1 and PEG1/C3S have increased due to the enhanced physicochemical interaction (Hendraningrat 2015). On the other hand, more stability of PEG2/C3S has reduced the percent of $\mathrm{Cl}(0.65 \%)$ on the glass bead substrate. The result of the treated the oil-wet glass bead by PEG1, PEG1/C3S, and PEG2/C3S is shown in Fig. 14a, b, and c, respectively. It is evident from Fig. 14b that the shape is cubic which covered the surface of the oil-wet glass bead due to agglomeration and precipitation of the PEG1/C3S (Cl 22.39\%). Remarkably, unlike the glass bead substrate, it is the small amount of $\mathrm{Cl}(1.42 \%)$ on the surface of treated oil-wet glass bead substrates by PEG1. Consequently, this may be due to the different negative charge of the glass bead and oil-wet glass bead surfaces (Bodratti et al. 2017; Watson et al. 2001; Yanagishima et al. 2012). Palmitic acid on the glass bead surface in the oil-wet glass bead substrates reduces the negative charge which consequently causes to decrease in the physicochemical interaction of the glass surface with $\mathrm{Na}$ and Cl. For treated oil-wet glass bead substrates in comparison with treated glass bead substrates, the percent of salt has been decreased for PEG1 94\%, PEG1/C3S 45\%, and PEG2/ C3S $48 \%$. This suggests that surface charge is an important parameter for the retention of substrates in the presence of salt (Fig. 15).

For PEG2/C3S, the amount of $\mathrm{Cl}$ on the oil-wet glass bead substrate $(\mathrm{Cl} 0.34 \%)$ was similar to the behavior of the glass bead substrate $(\mathrm{Cl} 0.65 \%)$. This result is very important 
(a) Glass bead in 2h treatment with PEG1 (2000 ppm salinity)
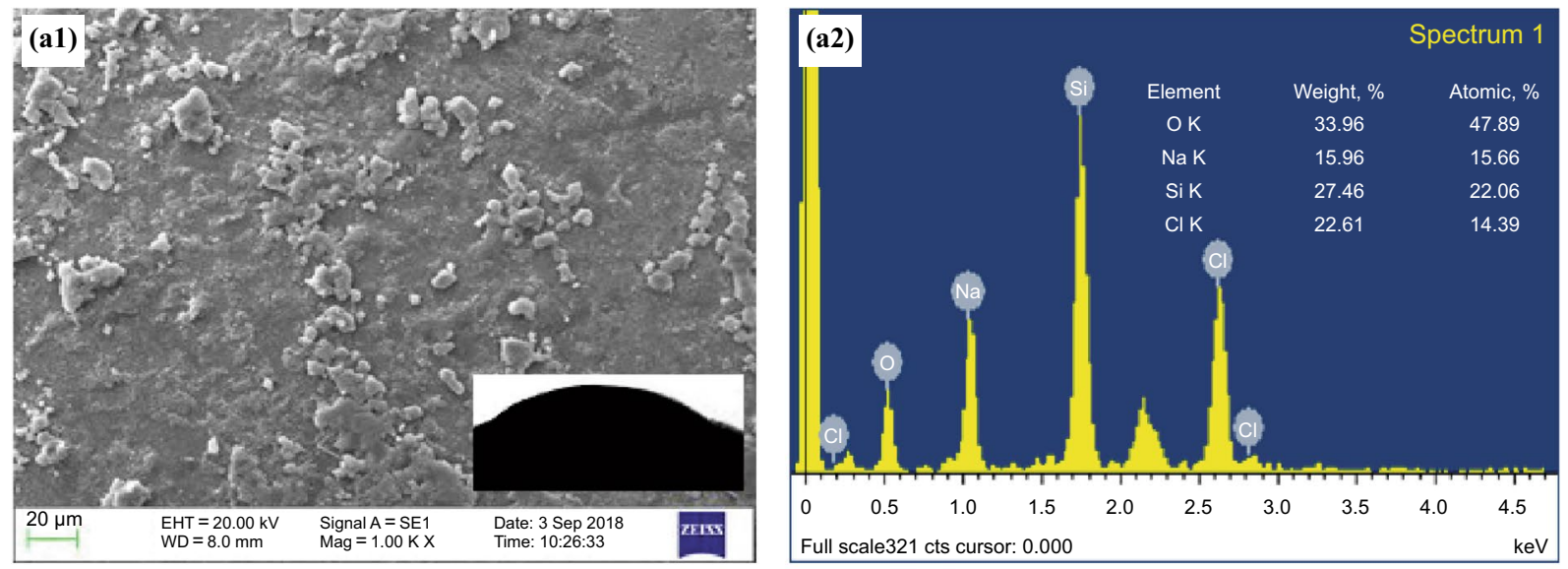

(b) Glass bead in $2 \mathrm{~h}$ treatment with PEG1/C3S (2000 ppm salinity)
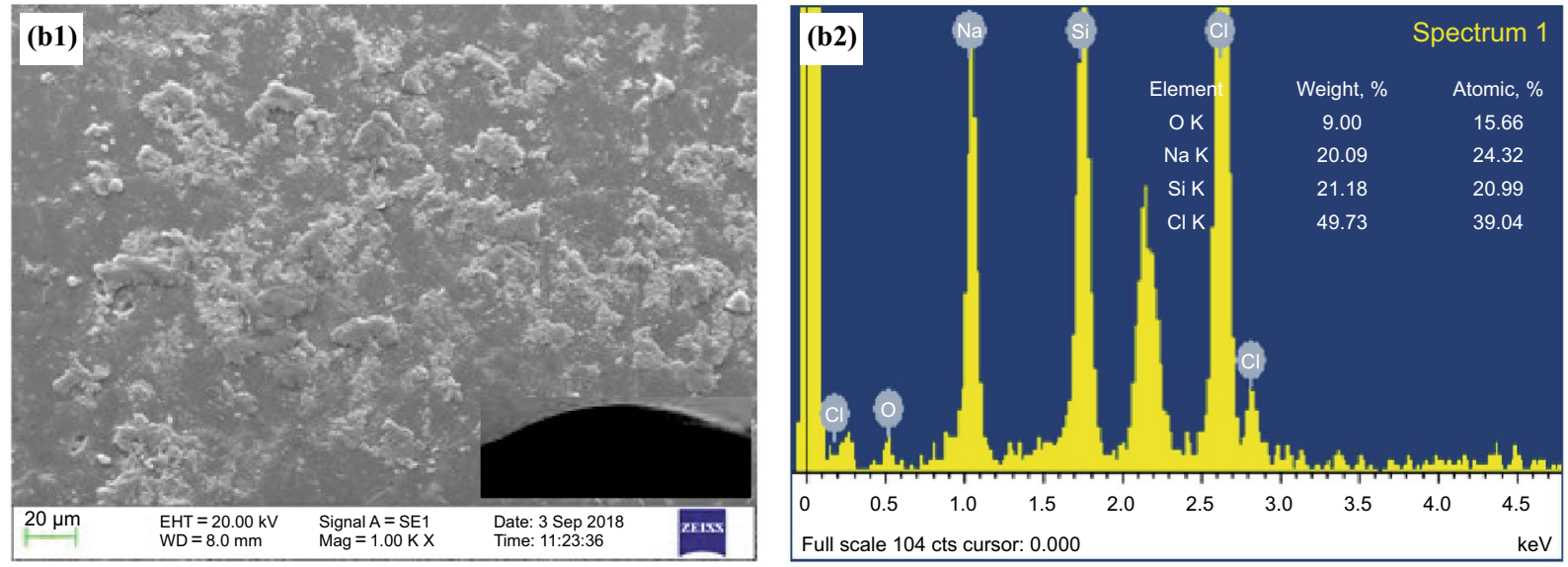

(c) Glass bead in $2 \mathrm{~h}$ treatment with PEG2/C3S (2000 ppm salinity)
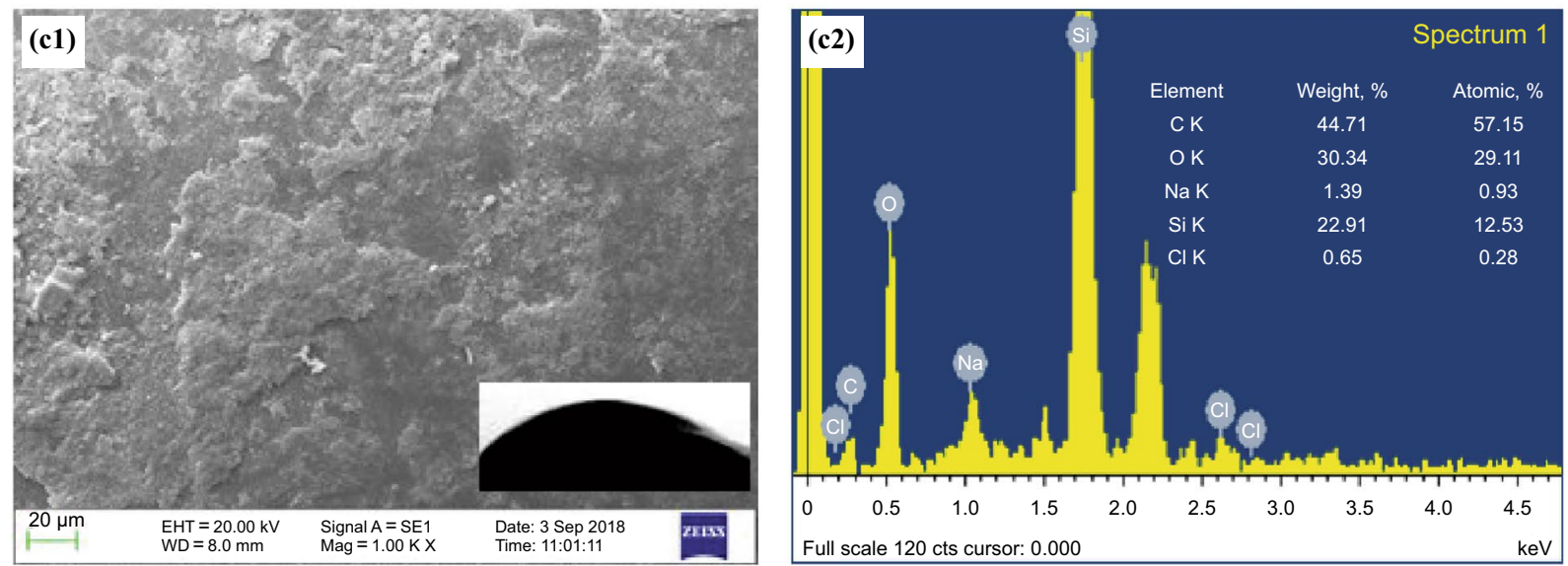

Fig. 13 SEM, EDS, and water contact angle $(\theta)$ of treated glass bead substrate in $2 \mathrm{~h}$ exposure time at $20,000 \mathrm{ppm} \mathrm{NaCl}$ concentration by a 3000 ppm polyethylene glycol methyl ether Mn 2000 (PEG1) b 3000 ppm mixed PEG1/trimethoxy (propyl) silane (C3S)-grafted silica, and c 1000 ppm mixed polyethylene glycol methyl ether Mn 5000 (PEG2)/C3S-grafted silica

because there is high salinity in oil reservoirs which can affect the retention process. In the case of nanoparticles modified with mixed polymer (PEG2/C3S), salinity shows less effect on the mechanism and amount of retention. This 
(a) Oil-wet glass bead in $2 \mathrm{~h}$ treatment with PEG1 (2000 ppm salinity)
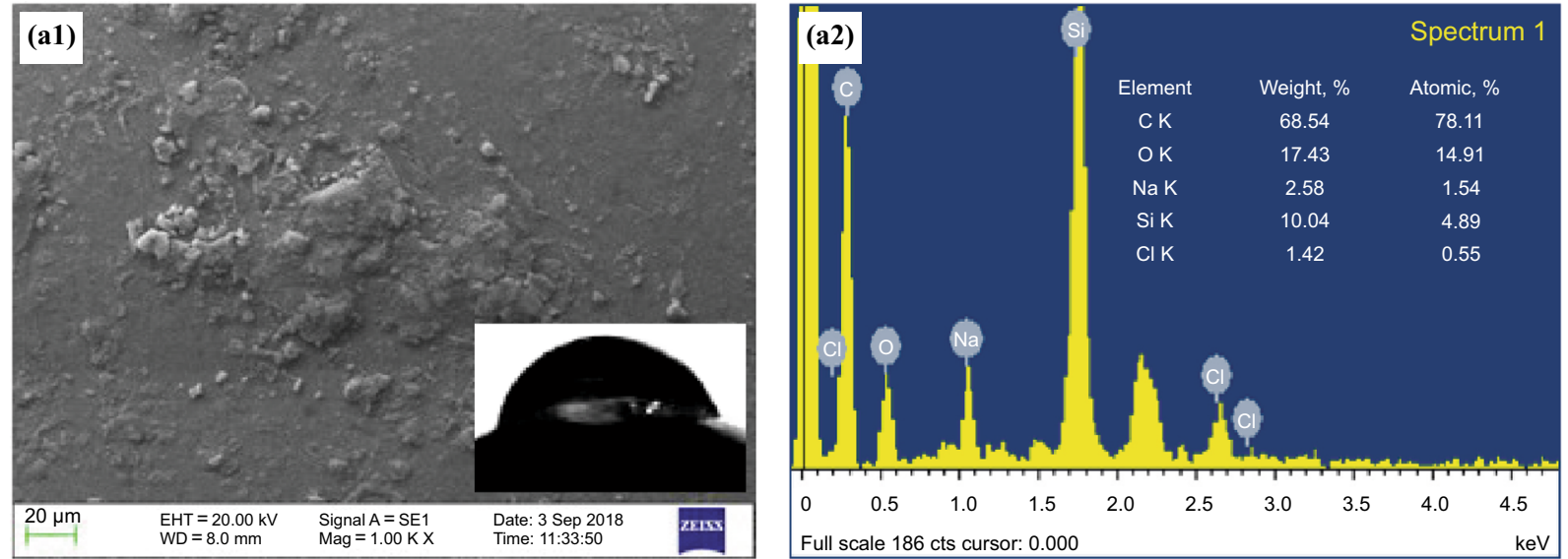

(b) Oil-wet glass bead in 2h treatment with PEG1/C3S (2000 ppm salinity)
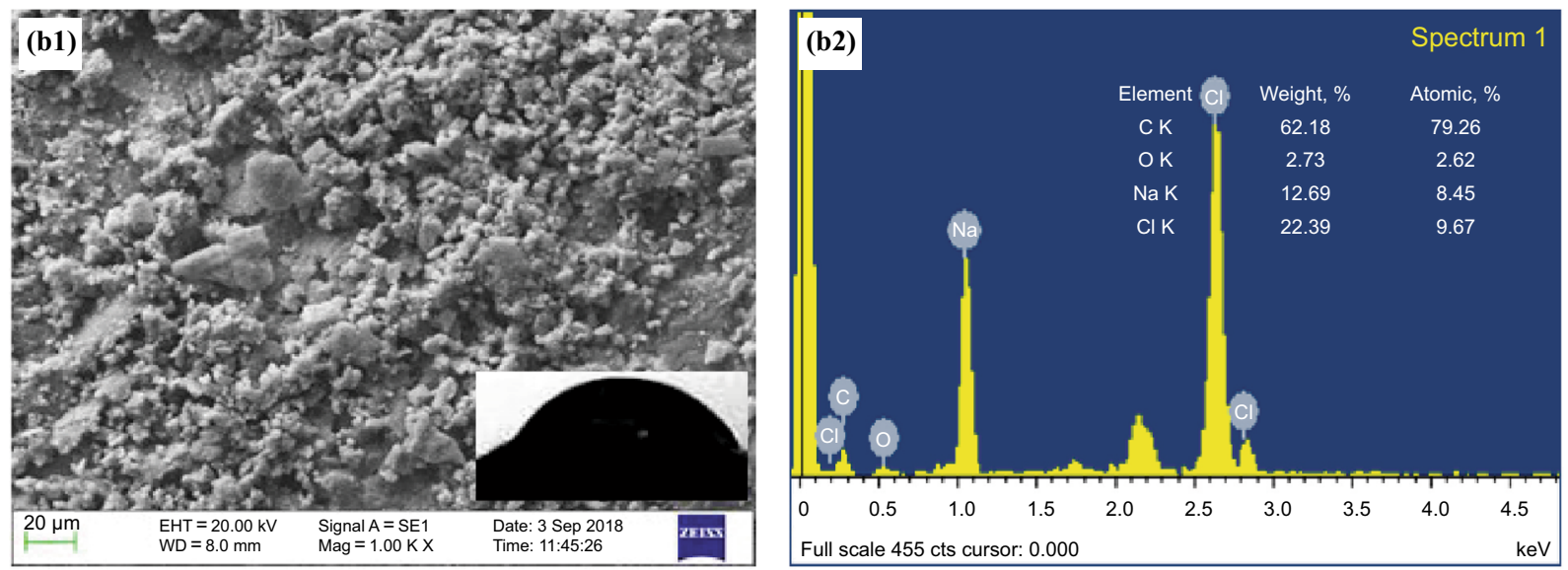

(c) Oil-wet glass bead in $2 \mathrm{~h}$ treatment with PEG2/C3S (2000 ppm salinity)
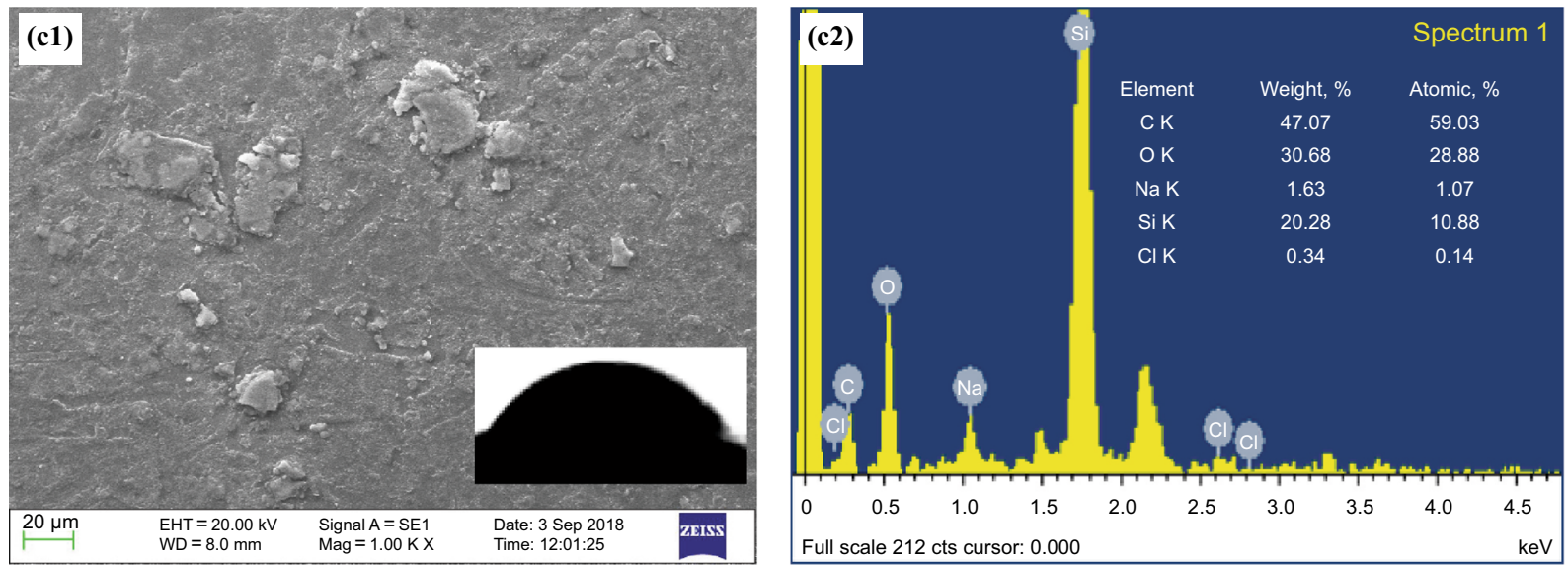

Fig. 14 SEM, EDS, and water contact angle $(\theta)$ of treated oil-wet glass bead substrate in $2 \mathrm{~h}$ exposure time at $20,000 \mathrm{ppm} \mathrm{NaCl} \mathrm{concentration} \mathrm{by}$ a 3000 ppm polyethylene glycol methyl ether Mn 2000 (PEG1) b 3000 ppm mixed PEG1/trimethoxy (propyl) silane (C3S)-grafted silica, and c 1000 ppm mixed polyethylene glycol methyl ether Mn 5000 (PEG2)/C3S-grafted silica

is due to the high colloidal stability of this nanofluid in comparison with other ones. Although high stability can decrease retention (Al-Anssari et al. 2017a), the hydrophobic propyl chains make the hydrophobic interaction which increases the absorption of nanofluids. As a conclusion, the selection of polymers with proper molecular weight and suitable wetting 
(a)

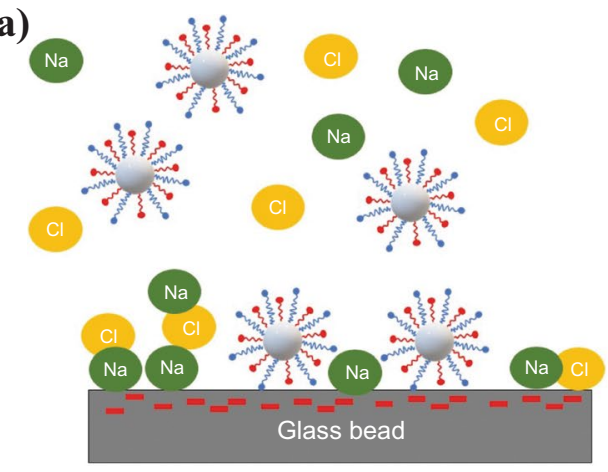

(b)

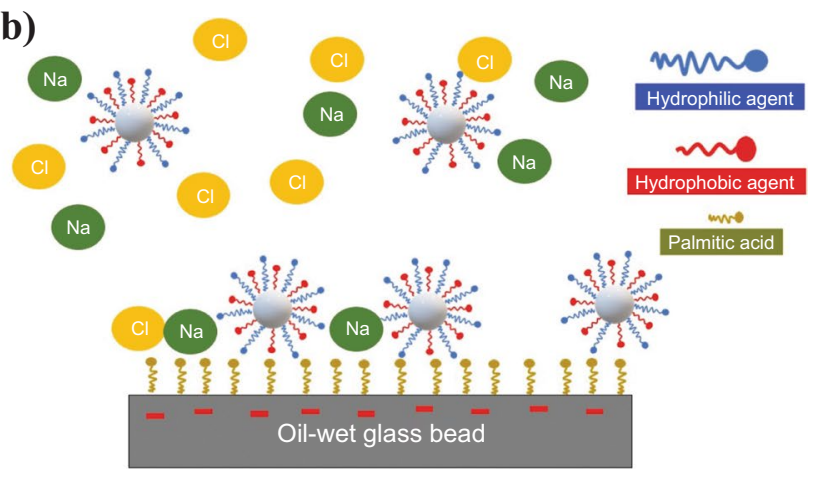

Fig. 15 Effect of negative charge of glass bead substrate on salt retention a Retention of salt and mixed polymer-coated silica nanoparticles on glass bead and $\mathbf{b}$ Retention of salt and mixed polymer-coated silica nanoparticles on oil-wet glass bead

properties can increase both colloidal stability and retention for the nanoparticles modified with polymers.

It is important to demonstrate the roles of retention and precipitation on the $\theta$ reduction of the substrates. In our experiment, retention of PEG2/C3S on the glass bead and the oil-wet glass bead substrates is the main reason for the $\theta$ reduction. One has to pay attention to this fact that for PEG1 and especially PEG1/C3S, precipitation has a major role in the $\theta$ reduction and retention of the glass bead and the oilwet glass bead substrates.

\section{Summary and conclusions}

Nanoparticles modified with mixed polymer are considered as a novel approach to increase hydrocarbon production from the reservoir rocks. This work presents a comprehensive study of the modified nanoparticles by polymers based on effective parameters, including the nanoparticles concentrations, surface modification time, and salinity. For these purposes, wettability alteration and retention of the modified silica nanoparticle by polyethylene glycol methyl ether average $\mathrm{Mn} \sim 2000$ (PEG1), the modified silica nanoparticle by mixed polyethylene glycol methyl ether average $\mathrm{Mn} \sim 2000$ and propyl chains (PEG1/C3S), and the modified silica nanoparticle by mixed polyethylene glycol methyl ether average $\mathrm{Mn} \sim 5000$ and propyl chains (PEG2/C3S) on simulated porous media by glass beads and oil-wet glass beads were studied. The following conclusions are as follow:

(1) The retention is enhanced along with an increase in the concentration of nanofluids and further water contact angle $(\theta)$ is decreased.

(2) The molecular weight of the polymer affects the retention of the substrate. In this research, the retention of nanofluid on substrates is enhanced with an increase in the molecular weight of polyethylene glycol methyl ether.

(3) The amount of propyl chains available in the mixed polymer is increased further retention of the nanofluids on oil-wet substrates. Propyl chains make hydrophobic interaction between the nanoparticles and the substrates. It can be proposed that the retention of silica modified with mixed polymer on the substrate will enhance with an increase in the hydrophobicity of the substrate.

(4) The stability of nanofluids has a great impact on the morphology of the adsorbed layer on the substrates. PEG2/C3S has more stability compared to PEG1 and PEG1/C3S causing a uniform distribution of the adsorbed nanoparticles on the substrates.

(5) The effect of salinity on the retention mechanism of nanofluids was investigated. According to the findings, the absorption mechanism of PEG2/C3S is slightly affected by salinity. Albeit, retention of PEG1 and especially PEG1/C3S is increased because of the enhanced physicochemical interactions.

(6) Investigation of morphology and composition of the treated substrates with PEG1 and PEG1/C3S revealed $\mathrm{Na}$ and $\mathrm{Cl}$ are available on the adsorbed layer. Due to the physicochemical interaction, salinity caused more retention for PEG1 and PEG1/C3S. Also, the performance of PEG2/C3S was better than that of PEG1, PEG1/C3S. The optimal concentration of this nanofluid was $1000 \mathrm{ppm}$ in a salinity range of 20,000$40,000 \mathrm{ppm}$, for the $\theta$ reduction of the glass bead and oil-wet glass bead from $62^{\circ}$ to $23^{\circ}$ and $114^{\circ}$ to $54^{\circ}$, respectively.

(7) It should be noted that pressure and temperature have a notable effect on nanofluid properties, especially at reservoir conditions. These observations were not considered in this study. Besides, reservoir rocks were replaced by glass beads. Thus, it can be experimen- 
tally predicted that practical nanofluid efficiency can be affected by rock heterogeneity, due to nanoparticle transport. Despite these assumptions, our study showed at salinity conditions, mixed polymer-grafted nanoparticles have better performance in comparison with polymer-grafted nanoparticles, especially in the oil-wet system. This observation is due to the hydrophobic interaction mechanism. As a total conclusion, this nanofluid can be considered as a promising agent for EOR purposes.

Open Access This article is licensed under a Creative Commons Attribution 4.0 International License, which permits use, sharing, adaptation, distribution and reproduction in any medium or format, as long as you give appropriate credit to the original author(s) and the source, provide a link to the Creative Commons licence, and indicate if changes were made. The images or other third party material in this article are included in the article's Creative Commons licence, unless indicated otherwise in a credit line to the material. If material is not included in the article's Creative Commons licence and your intended use is not permitted by statutory regulation or exceeds the permitted use, you will need to obtain permission directly from the copyright holder. To view a copy of this licence, visit http://creativecommons.org/licenses/by/4.0/.

\section{References}

Afsharian-Moghaddam H, Haddadi-Asl V. Direct synthesis of polymergrafted inorganic hybrids via reversible chain transfer catalyzed polymerization. Iran Polym J. 2013;22(10):757-66. https://doi. org/10.1007/s13726-013-0176-9.

Aftab A, Ismail AR, Ibupoto Z, Akeiber H, Malghani M. Nanoparticles based drilling muds a solution to drill elevated temperature wells: a review. Renew Sust Energy Rev. 2017;76:1301-13. https://doi.org/10.1016/j.rser.2017.03.050.

Agista MN, Guo K, Yu Z. A state-of-the-art review of nanoparticles application in petroleum with a focus on enhanced oil recovery. Appl Sci. 2018;8(6):871. https://doi.org/10.3390/app8060871.

Al-Anssari S, Arif M, Wang S, Barifcani A, Iglauer S. Stabilising nanofluids in saline environments. J Colloid Interf Sci. 2017a;508:222-9. https://doi.org/10.1016/j.jcis.2017.08.043.

Al-Anssari S, Arif M, Wang S, Barifcani A, Lebedev M, Iglauer S. Wettability of nano-treated calcite/ $\mathrm{CO}_{2} /$ brine systems: implication for enhanced $\mathrm{CO}_{2}$ storage potential. Int J Greenh Gas Con. 2017b;66:97-105. https://doi.org/10.1016/j.ijggc.2017.09.008.

Al-Anssari S, Arif M, Wang S, Barifcani A, Lebedev M, Iglauer S. Wettability of nanofluid-modified oil-wet calcite at reservoir conditions. Fuel. 2018;211:405-14. https://doi.org/10.1016/j. fuel.2017.08.111.

Al-Anssari S, Barifcani A, Wang S, Maxim L, Iglauer S. Wettability alteration of oil-wet carbonate by silica nanofluid. J Colloid Interf Sci. 2016;461:435-42. https://doi.org/10.1016/j. jcis.2015.09.051.

Al-Anssari S, Wang S, Barifcani A, Lebedev M, Iglauer S. Effect of temperature and $\mathrm{SiO}_{2}$ nanoparticle size on wettability alteration of oil-wet calcite. Fuel. 2017c;206:34-42. https://doi.org/10.1016/j. fuel.2017.05.077.
Arslan G, Özmen M, Gündüz B, Zhang X, Ersöz M. Surface modification of glass beads with an aminosilane monolayer. Turk J Chem. 2006;30(2):203-10.

Bagaria HG, Neilson BM, Worthen AJ, Xue Z, Yoon KY, Cheng $\mathrm{V}$, et al. Adsorption of iron oxide nanoclusters stabilized with sulfonated copolymers on silica in concentrated $\mathrm{NaCl}$ and CaCl2 brine. J Colloid Interf Sci. 2013;398:217-26. https://doi. org/10.1016/j.jcis.2013.01.056.

Behzadi A, Mohammadi A. Environmentally responsive surface-modified silica nanoparticles for enhanced oil recovery. J Nanopart Res. 2016;18(9):266. https://doi.org/10.1007/s11051-016-3580-1.

Binks BP, Rodrigues JA. Enhanced stabilization of emulsions due to surfactant-induced nanoparticle flocculation. Langmuir. 2007;23(14):7436-9. https://doi.org/10.1021/la700597k.

Binks BP, Rodrigues JA, Frith WJ. Synergistic interaction in emulsions stabilized by a mixture of silica nanoparticles and cationic surfactant. Langmuir. 2007;23(7):3626-36. https://doi.org/10.1021/ la0634600.

Bodratti AM, Sarkar B, Alexandridis P. Adsorption of poly (ethylene oxide)-containing amphiphilic polymers on solid-liquid interfaces: fundamentals and applications. Adv Colloid Interface. 2017;244:132-63. https://doi.org/10.1016/j.cis.2016.09.003.

Buijse MA, Tandon K, Jain S, Handgraaf J-W, Fraaije J, editors. Surfactant optimization for EOR using advanced chemical computational methods. In: SPE Improved oil recovery symposium; 2012: Society of Petroleum Engineers Journal. https://doi. org/10.2118/154212-ms.

Choi SK, Son HA, Kim HT, Kim JW. Nanofluid enhanced oil recovery using hydrophobically associative zwitterionic polymer-coated silica nanoparticles. Energy Fuel. 2017;31(8):7777-82. https:// doi.org/10.1021/acs.energyfuels.7b00455.

Ehtesabi H, Ahadian MM, Taghikhani V, Ghazanfari MH. Enhanced heavy oil recovery in sandstone cores using $\mathrm{TiO}_{2}$ nanofluids. Energy Fuel. 2014;28(1):423-30. https://doi.org/10.1021/ef401 $338 \mathrm{c}$.

El-Hoshoudy A, Desouky S, Betiha M, Alsabagh A. Use of 1-vinyl imidazole based surfmers for preparation of polyacrylamide- $\mathrm{SiO}_{2}$ nanocomposite through aza-Michael addition copolymerization reaction for rock wettability alteration. Fuel. 2016;170:161-75. https://doi.org/10.1016/j.fuel.2015.12.036.

Foster LM, Worthen AJ, Foster EL, Dong J, Roach CM, Metaxas AE, et al. High interfacial activity of polymers "grafted through" functionalized iron oxide nanoparticle clusters. Langmuir. 2014;30(34):10188-96. https://doi.org/10.1021/la501445f.

Giraldo J, Benjumea P, Lopera S, Cortés FB, Ruiz MA. Wettability alteration of sandstone cores by alumina-based nanofluids. Energy Fuel. 2013;27(7):3659-65. https://doi.org/10.1021/ef4002956.

Guo K, Li H, Yu Z. In-situ heavy and extra-heavy oil recovery: a review. Fuel. 2016;185:886-902. https://doi.org/10.1016/j. fuel.2016.08.047.

Hendraningrat L. Unlocking the Potential of Hydrophilic Nanoparticles as Novel Enhanced Oil Recovery Method: An Experimental Investigation. 2015.

Hendraningrat L, Shidong L, Torsaeter O, editors. A glass micromodel experimental study of hydrophilic nanoparticles retention for EOR project. SPE Russian Oil and Gas Exploration and Production Technical Conference and Exhibition; 2012: Society of Petroleum Engineers Journal. https://doi.org/10.2118/159161-ms.

Hendraningrat L, Torsæter O. Effects of the initial rock wettability on silica-based nanofluid-enhanced oil recovery processes at reservoir temperatures. Energy Fuel. 2014;28(10):6228-41. https://doi. org/10.1021/ef5014049.

Hendraningrat L, Torsæter O. Metal oxide-based nanoparticles: revealing their potential to enhance oil recovery in different wettability systems. Appl Nanosci. 2015;5(2):181-99. https://doi. org/10.1007/s13204-014-0305-6. 
Iglauer S, Pentland C, Busch A. $\mathrm{CO}_{2}$ wettability of seal and reservoir rocks and the implications for carbon geo-sequestration. Water Resour Res. 2015;51(1):729-74. https://doi.org/10.1002/2014W R015553.

Iglauer S, Wu Y, Shuler P, Tang Y, Goddard WA III. Alkyl polyglycoside surfactant-alcohol cosolvent formulations for improved oil recovery. Colloid Surface A. 2009;339(1-3):48-59. https://doi. org/10.1016/j.colsurfa.2009.01.015.

Jamaloei BY, Kharrat R. Analysis of microscopic displacement mechanisms of dilute surfactant flooding in oil-wet and water-wet porous media. Transport Porous Med. 2010;81(1):1. https://doi. org/10.1007/s11242-009-9382-5.

Ju B, Dai S, Luan Z, Zhu T, Su X, Qiu X, editors. A study of wettability and permeability change caused by adsorption of nanometer structured polysilicon on the surface of porous media. SPE Asia Pacific oil and gas conference and exhibition; 2002: Society of Petroleum Engineers Journal. https://doi.org/10.2118/77938-ms.

Ju B, Fan T, Ma M. Enhanced oil recovery by flooding with hydrophilic nanoparticles. China Particuol. 2006;4(1):41-6. https://doi. org/10.1016/S1672-2515(07)60232-2.

Kazemzadeh Y, Shojaei S, Riazi M, Sharifi M. Review on application of nanoparticles for EOR purposes; a critical of the opportunities and challenges. CHINESE J CHEM ENG 2018;10. https:// doi.org/10.1016/j.cjche.2018.05.022.

Kim D, Krishnamoorti R. Interfacial Activity of Poly [oligo (ethylene oxide)-monomethyl ether methacrylate]-Grafted Silica Nanoparticles. Ind Eng Chem Res. 2015;54(14):3648-56. https ://doi.org/10.1021/acs.iecr.5b00105.

Mader-Arndt K, Kutelova Z, Fuchs R, Meyer J, Staedler T, Hintz W, et al. Single particle contact versus particle packing behavior: model based analysis of chemically modified glass particles. Granul Matter. 2014;16(3):359-75. https://doi.org/10.1007/ s10035-013-0478-9.

McElfresh PM, Holcomb DL, Ector D, editors. Application of nanofluid technology to improve recovery in oil and gas wells. SPE international oilfield nanotechnology conference and exhibition; 2012: Society of Petroleum Engineers Journal. https://doi. org/10.2118/154827-ms.

Miranda CR, Lara LSd, Tonetto BC, editors. Stability and mobility of functionalized silica nanoparticles for enhanced oil recovery applications. SPE international oilfield nanotechnology conference and exhibition; 2012: Society of Petroleum Engineers Journal. https://doi.org/10.2118/157033-ms.

Mirshahghassemi S, Lead JR. Oil recovery from water under environmentally relevant conditions using magnetic nanoparticles. Int J Environ Sci Te. 2015;49(19):11729-36. https://doi. org/10.1021/acs.est.5b02687.

Mondragon R, Julia JE, Barba A, Jarque JC. Characterization of silica-water nanofluids dispersed with an ultrasound probe: a study of their physical properties and stability. Powder Technol. 2012;224:138-46. https://doi.org/10.1016/j.powte c. 2012.02 .043 .

Munshi A, Singh V, Kumar M, Singh J. Effect of nanoparticle size on sessile droplet contact angle. J Appl Phys. 2008;103(8):084315. https://doi.org/10.1063/1.2912464.

Nikolov A, Kondiparty K, Wasan D. Nanoparticle self-structuring in a nanofluid film spreading on a solid surface. Langmuir. 2010;26(11):7665-70. https://doi.org/10.1021/la100928t.

Nwidee LN, Al-Anssari S, Barifcani A, Sarmadivaleh M, Lebedev $\mathrm{M}$, Iglauer S. Nanoparticles influence on wetting behaviour of fractured limestone formation. J Pet Sci Eng. 2017;149:782-8. https://doi.org/10.1016/j.petrol.2016.11.017.

Omurlu C, Pham H, Nguyen Q. Interaction of surface-modified silica nanoparticles with clay minerals. Appl Nanosci. 2016;6(8):116773. https://doi.org/10.1007/s13204-016-0534-y.
Palchoudhury S, Lead JR. A facile and cost-effective method for separation of oil-water mixtures using polymer-coated iron oxide nanoparticles. Environ Sci Technol. 2014;48(24):14558-63. https ://doi.org/10.1021/es5037755.

Parfitt R, Greenland D. The adsorption of poly (ethylene glycols) on clay minerals. Clay Miner. 1970;8(3):305-15. https://doi. org/10.1180/claymin.1970.008.3.08.

Patel J, Borgohain S, Kumar M, Rangarajan V, Somasundaran P, Sen R. Recent developments in microbial enhanced oil recovery. Renew Sust Energy Rev. 2015;52:1539-58. https://doi.org/10.1016/j. rser.2015.07.135.

Qi C, Liu M, Wang G, Pan Y, Liang L. Experimental research on stabilities, thermophysical properties and heat transfer enhancement of nanofluids in heat exchanger systems. Chin J Chem Eng. 2018;26(12):2420-30. https://doi.org/10.1016/j.cjche .2018.03.021.

Rabe M, Verdes D, Seeger S. Understanding protein adsorption phenomena at solid surfaces. Adv Colloid Interface. 2011;162(12):87-106. https://doi.org/10.1016/j.cis.2010.12.007.

Ranka M, Brown P, Hatton TA. Responsive stabilization of nanoparticles for extreme salinity and high-temperature reservoir applications. ACS Appl Mater. 2015;7(35):19651-8. https://doi. org/10.1021/acsami.5b04200.

Richard E, Aruna S, Basu BJ. Superhydrophobic surfaces fabricated by surface modification of alumina particles. Appl Surf Sci. 2012;258(24):10199-204. https://doi.org/10.1016/j.apsus c.2012.07.009.

Rostami M, Mohseni M, Ranjbar Z. Investigating the effect of $\mathrm{pH}$ on the surface chemistry of an amino silane treated nano silica. Pigm Resin Technol. 2011. https://doi.org/10.1108/036994211111805 09.

Roustaei A, Bagherzadeh $\mathrm{H}$. Experimental investigation of $\mathrm{SiO}_{2}$ nanoparticles on enhanced oil recovery of carbonate reservoirs. J Pet Explor Prod Technol. 2015;5(1):27-33. https://doi.org/10.1007/ s13202-014-0120-3.

Rubio N, Au H, Leese HS, Hu S, Clancy AJ, Shaffer MS. Grafting from versus grafting to approaches for the functionalization of graphene nanoplatelets with poly (methyl methacrylate). Macromolecules. 2017;50(18):7070-9. https://doi.org/10.1021/acs. macromol.7b01047.

Salager JL, Marquez N, Graciaa A, Lachaise J. Partitioning of ethoxylated octylphenol surfactants in microemulsion - oil - water systems: influence of temperature and relation between partitioning coefficient and physicochemical formulation. Langmuir. 2000;16(13):5534-9. https://doi.org/10.1021/la9905517.

Shi X, Rosa R, Lazzeri A. On the coating of precipitated calcium carbonate with stearic acid in aqueous medium. Langmuir. 2010;26(11):8474-82. https://doi.org/10.1021/la904914h.

Songolzadeh R, Moghadasi J. Stabilizing silica nanoparticles in high saline water by using ionic surfactants for wettability alteration application. Colloid Polym Sci. 2017;295(1):145-55. https://doi. org/10.1007/s00396-016-3987-3.

Wang D, Duan H, Möhwald H. The water/oil interface: the emerging horizon for self-assembly of nanoparticles. Soft Matter. 2005;1(6):412-6. https://doi.org/10.1039/B511911A.

Watson H, Norström A, Torrkulla A, Rosenholm J. Aqueous amino silane modification of E-glass surfaces. J Colloid Interface Sci. 2001;238(1):136-46. https://doi.org/10.1006/jcis.2001.7506.

Xue Z, Foster E, Wang Y, Nayak S, Cheng V, Ngo VW, et al. Effect of grafted copolymer composition on iron oxide nanoparticle stability and transport in porous media at high salinity. Energy Fuel. 2014;28(6):3655-65. https://doi.org/10.1021/ef500340h.

Yanagishima T, Di Michele L, Kotar J, Eiser E. Diffusive behaviour of PLL-PEG coated colloids on $\lambda$-DNA brushes-tuning hydrophobicity. Soft Matter. 2012;8(25):6792-8. https://doi.org/10.1039/ C2SM25296A. 
Zargartalebi M, Kharrat R, Barati N. Enhancement of surfactant flooding performance by the use of silica nanoparticles. Fuel. 2015;143:21-7. https://doi.org/10.1016/j.fuel.2014.11.040.

Zhang H, Ramakrishnan T, Nikolov A, Wasan D. Enhanced oil displacement by nanofluid's structural disjoining pressure in model fractured porous media. J Colloid Interf Sci. 2018;511:48-56. https://doi.org/10.1016/j.jcis.2017.09.067.
Zhao X, Blunt MJ, Yao J. Pore-scale modeling: effects of wettability on waterflood oil recovery. J Pet Sci Eng. 2010;71(3-4):169-78. https://doi.org/10.1016/j.petrol.2010.01.011.

Zhu X, Zhang Q, Wang Y, Wei F. Review on the nanoparticle fluidization science and technology. Chin J Chem Eng. 2016;24(1):9-22. https://doi.org/10.1016/j.cjche.2015.06.005. 